\title{
Implementing organ-on-chip in a next-generation risk assessment of chemicals: a review
}

\author{
Katharina S. Nitsche ${ }^{1}\left[\right.$ ] Iris Müller $^{2} \cdot$ Sophie Malcomber ${ }^{2} \cdot$ Paul L. Carmichael $^{1,2} \cdot$ Hans Bouwmeester $^{1}$
}

Received: 11 January 2022 / Accepted: 20 January 2022 / Published online: 1 February 2022

(c) The Author(s) 2022

\begin{abstract}
Organ-on-chip (OoC) technology is full of engineering and biological challenges, but it has the potential to revolutionize the Next-Generation Risk Assessment of novel ingredients for consumer products and chemicals. A successful incorporation of OoC technology into the Next-Generation Risk Assessment toolbox depends on the robustness of the microfluidic devices and the organ tissue models used. Recent advances in standardized device manufacturing, organ tissue cultivation and growth protocols offer the ability to bridge the gaps towards the implementation of organ-on-chip technology. Next-Generation Risk Assessment is an exposure-led and hypothesis-driven tiered approach to risk assessment using detailed human exposure information and the application of appropriate new (non-animal) toxicological testing approaches. Organ-on-chip presents a promising in vitro approach by combining human cell culturing with dynamic microfluidics to improve physiological emulation. Here, we critically review commercial organ-on-chip devices, as well as recent tissue culture model studies of the skin, intestinal barrier and liver as the main metabolic organ to be used on-chip for Next-Generation Risk Assessment. Finally, microfluidically linked tissue combinations such as skin-liver and intestine-liver in organ-on-chip devices are reviewed as they form a relevant aspect for advancing toxicokinetic and toxicodynamic studies. We point to recent achievements and challenges to overcome, to advance non-animal, human-relevant safety studies.
\end{abstract}

Keywords Microfluidics $\cdot$ Organ-on-chip $\cdot$ Next-generation risk assessment $\cdot$ Skin-on-chip $\cdot$ Gut-on-chip $\cdot$ Liver-on-chip

\section{Introduction}

Organ-on-chip $(\mathrm{OoC})$ technologies attract increasing interest as human, physiologically relevant in vitro testing systems to be incorporated in a Next-Generation Risk Assessment (NGRA) of chemicals. OoC are small scale devices designed for dynamic human cell culture that can simulate different microenvironments and functions in such a way that the cells can behave as naturally as possible (i.e., more in vivo-like) (Mummery et al. 2020). The "natural" microenvironment and functions are introduced to the cells in the OoCs, using microfluidic flow, 3D tissue reconstruction and the use of multiple cell types and cell sources. OoC hardware devices

Katharina S. Nitsche

katharina.nitsche@wur.nl

1 Division of Toxicology, Wageningen University, P.O.

Box 8000, 6700 EA Wageningen, The Netherlands

2 Unilever Safety and Environmental Assurance Centre, Colworth Science Park, Sharnbrook, Bedfordshire MK44 1LQ, UK vary on the materials used (e.g., rubber, plastic, silicone, glass), layout (open or closed culture compartments), perfusion (active or passive) and can provide different support for cell culturing on chip (e.g., stretch, peristaltic, contraction dynamics etc.). In the last decade, numerous published microfluidic chip approaches have accelerated the innovation and commercial large-scale production of these devices (see "Commercially manufactured $\mathrm{OoC}$ devices"). This resulted in an increasing infrastructural development for biomedical laboratories without the need of in-house microfluidic designing expertise. In parallel, recent publications using human cells in OoC devices underpin the advances in biology by demonstrating that the induced biochemical and mechanical cues improve functional and structural characteristics of tissue cultures. The combination of both, tissue function with flow dynamics in 3D architecture, may significantly contribute to the transition of animal-free approaches for regulatory safety assessment (e.g., development of adverse outcome pathways) (Heringa et al. 2020). In addition, $\mathrm{OoC}$ might also accelerate new approach methodology acceptance for NGRA, defined as human-relevant, exposure-led, hypothesis driven risk assessment approach 
that integrates in silico, in chemico and in vitro approaches for assessing effects on human health (Berggren et al. 2017; Dent et al. 2018; Thomas et al. 2019). In this tiered approach, OoC systems have value in the higher tier ab initio approach for targeted testing, biokinetic refinements, as well as the estimation of the points of departure, uncertainty, margin of safety and extrapolation (Berggren et al. 2017). Yet, there is a clear consensus in the $\mathrm{OoC}$ community, (consumer) industry and regulatory bodies on the need for standardisation to advance the field (Piergiovanni et al. 2021).

The review we focus on data available from OoC manufacturer websites, as well as on the search for current (2016-2021) tissue-specific studies including different cell lines and types in skin, intestine and gut models. With the review, we aim to evaluate the features and robustness of the currently available manufactured $\mathrm{OoC}$ devices and skin, intestine and liver tissue models that can be used as part of the NGRA toolbox and at higher tier testing on-chip (see selection in tables and figures). First, we describe commercially manufactured $\mathrm{OoC}$ devices that thus have a (more) standardized design and critically discuss the applicability of these devices for toxicological studies. Next, some promising achievements with microfluidic in vitro tissue culturing approaches are highlighted. For this analysis, we focussed on two important biological barriers, the skin and gastrointestinal epithelium, as these are of particular relevance for safety assessment that cannot use laboratory animal-derived data. In addition, liver models were reviewed as they represent the most metabolically active tissue, which is a key characteristic if systemic toxicology is considered. Finally, fluidically linked tissue combinations such as skin-liver and intestine-liver in $\mathrm{OoC}$ devices are reviewed as they form an innovative aspect for advancing and integrating kinetics studies, which are needed to increase the physiological relevance of in vitro models. We conclude this review by listing additional research and standardization that are required to qualify $\mathrm{OoC}$ as fit-for-purpose systems in a NGRA toolbox.

\section{Commercially manufactured OoC devices}

Due to the broad need for human-relevant in vitro approaches for different research applications, the development of novel devices is constantly stimulated. A decade after the first successfully lab-fabricated $\mathrm{OoC}$, a wide variety of commercially manufactured hardware became available to emulate a more natural microenvironment for in vitro studies (Mummery et al. 2020). The hardware design of an OoC is dictated by the microenvironment required for optimum cellular functions, the monitoring parameters and the research application. The design of the hardware in turn determines the material selection (e.g., rubber, plastic, silicone and glass) with its associated fabrication technique (e.g., Lithography, 3D printing) and the options for stimulating and sensing (e.g., mechanical, optical), as well as the interfacing layout (e.g., open- or closed culture compartment accessibility, liquid perfusion) (Kurth et al. 2020). Based on the material selection and interfacing, we will discuss commercially manufactured devices, as shown in Fig. 1.

\section{Materials used for OoC devices}

Not all materials are suitable for an OoC fabrication as they must support the growth of functional cells and allow the study of the biological model in this simplified microenvironment (Kurth et al. 2020). The material selection must consider the creation of appropriate culture chambers and with fluidic connection, induced forces and stiffness to recreate biological functions, as well as potentially adding electrical stimuli and actuation to control and observe the created biological tissue model. The culture chambers are the advanced compartments that are often separated by porous membranes to host the cultured tissue, partially with the help of a biological scaffold. In these culture compartments the cell tissue is provided with the necessary nutrients, waste products are removed and a (bio)chemical environments (e.g., gradients) can be simulated (e.g., oxygen, carbon dioxide, acidity etc.) (Mummery et al. 2020). It is rare that a single material can be used to fabricate an entire complex OoC device, including the culture compartment and fluidic connections with mechanics and sensors, as multiple criteria must be considered in the material selection and integration. Material criteria include the biocompatibility, sterilization, physiochemical properties, material function on the device and eventually the costs. For (novel) material used in $\mathrm{OoC}$, biocompatibility implies that the material supports appropriate cellular activity without undesired or harmful biological effects (Zhang et al. 2018; Kurth et al. 2020). As the material is in direct or close contact with cells, it is necessary to avoid contamination, and therefore, it is important that the material must withstand sterilisation techniques. Essential physiochemical properties are optical transparency for observation, gas permeability for cells requiring oxygen, lowest possible absorption of molecules, chemical and thermal resistance, as well as stiffness. As mentioned earlier in this section, these requirements largely depend on the chip design and research application. Currently, common materials used for creating $\mathrm{OoC}$ devices are silicone substrates and polymers (e.g., PDMS), resins and glass partly meet the required criteria [see Azizipour et al. (2020) and Ding et al. (2020)]. Further improvements are needed and novel (hybrid) material may fulfil the various engineering and biological requirements (Ding et al. 2020; Grant et al. 2021). 
Fig. 1 Examples of commercially available OoC devices for different research applications $\mathbf{A}$ OrganoPlate ${ }^{\circledR}$ 3-lanelMimetas (2020) B Organs-on-Chips TechnologylEmulate (2020) C PhysioMimix ${ }^{\mathrm{TM}} \mid \mathrm{CN}$ BIO Innovations (2020) D HUMIMIC Chip2/TissUse GmbH (2022) E Akura $^{\mathrm{TM}}$ Flow: Transforming Drug Discovery and Development with Body-on-a-Chip Technology|InSphero (2020) F Organ-on-a-chiplMicronit (2020) G The QV900IIdeal for high-content experiments and industrial uselKirkstall Ltd (2020) H Products-Bi/ond (2020) I The ParVivo ${ }^{\text {TM }}$ Organon-Chip TechnologylNortis Bio (2020) J HuDMOP®IIONTOX (2022). All pictures taken from the websites of manufacturers (see references)
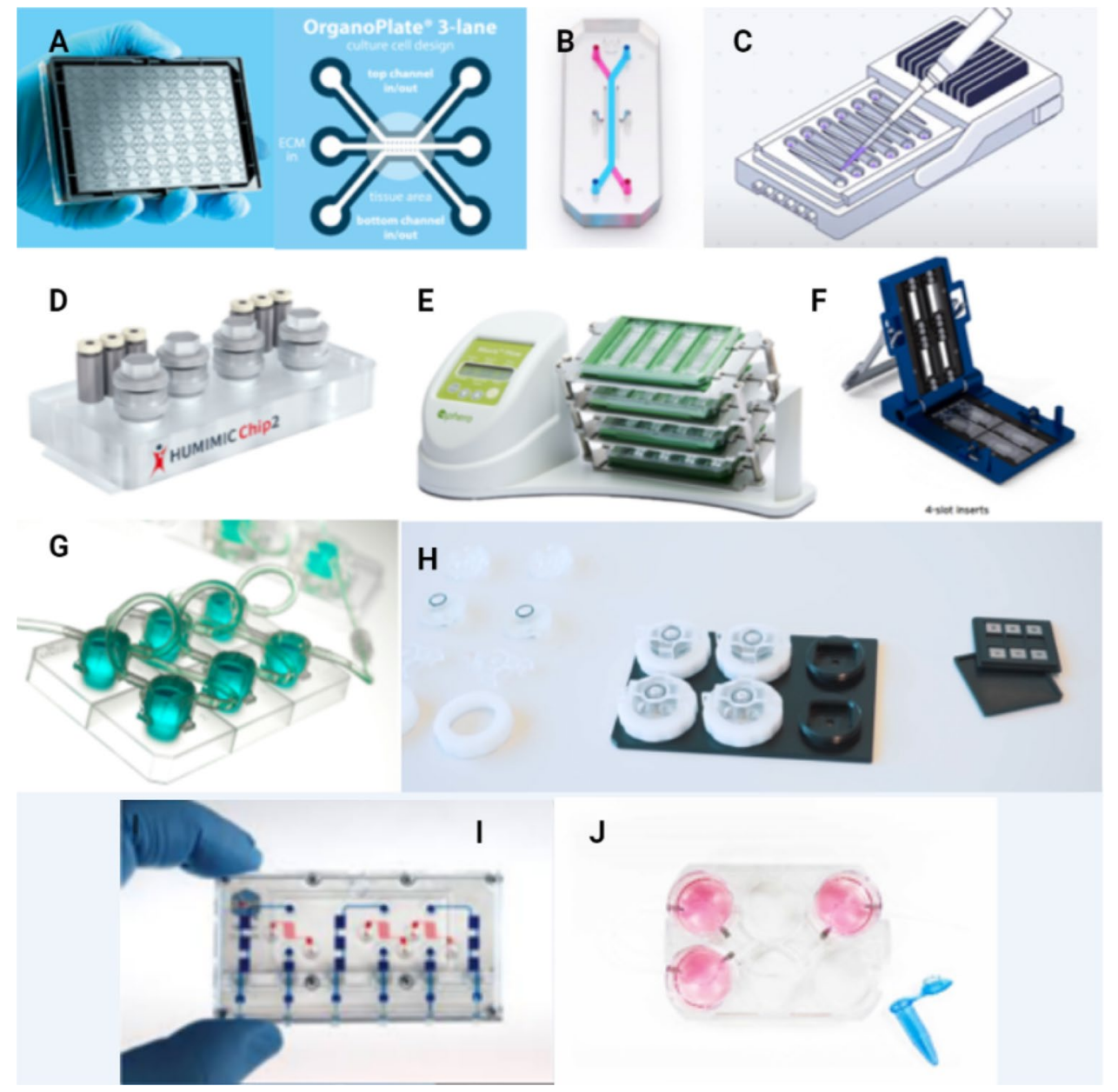

\section{Open and closed tissue culture compartments}

All device manufacturers strive for different layouts to target different research applications. This leads to at least two major design differences in layout for the tissue culture compartments access: an open or closed access. As to be seen in the devices C, D, E, F, G, H, J, as depicted in Fig. 1, the open culture compartment offers a direct access for seeding, sampling, dosing and analysis. This layout partially facilitates air-liquid interfacing for skin and gut, the seeding of bigger cell aggregates such as liver spheroids and the layering of dermal and intestinal cell sheets on an insertable membrane as reviewed by Berthier et al. (2019). The closed layouts (see Fig. 1A, B, I) can mimic better a closed 3D organ architectures and mechanical forces, such as flow and stretch for intestinal, liver and vascular tissues. However, this closed layout complicates the extraction of cell samples for analysis (Bhatia and Ingber 2014). The open or closed tissue culture compartment access also impacts the requirement for tubing and pumps for fluidic perfusion.

\section{Fluidic perfusion of the devices}

Fluidic perfusion ensures the continuous supply of nutrients and removal of waste products from the cell culture. In addition, perfusion delivers mechanical stimuli by generating laminar, pulsative and interstitial shear stress along the microfluidic channel thus recreating living cell environments with biochemical gradients and cell signaling (Rothbauer et al. 2018). Perfusion methods are either passive or active through direct integration or plugged-in system to actuate the fluidic flow as reviewed by Kurth et al. (2020). The simplest and least-expensive method is gravity-driven which uses mostly a rocking platform to induce the passive flow (see Fig. 1A, E). The induced bidirectional flow results from the difference in liquid height between the fluid inlet and outlet within an closed culture compartments (Kaarj and Yoon 2019). Mechanical active perfusion through directly integrated or plugged-in pneumatic and peristaltic pumps offer a simple solution to deliver culture medium from source to waste or to recirculate the culture medium. A number of cell tissues can be perfused in parallel, depending 
either on the amount of tubing which can be coiled around the peristaltic pump or the microvalve amount connected to the pressure controlled pneumatic pump (also on-chip) (see Fig. 1B-D, F-J). Both, passive and active perfusion inherent limitations in their fluid handling as reviewed by Soenksen et al. (2018). For example, mechanical pumps (also directly on-chip) connected to open wells or channels usually do not deliver robust steady-state flows for long periods of time as they rely on pulsative flows (e.g., directly integrated or plugin pumps), extra tubing and are more susceptible to contamination and air-bubbles (Mäki et al. 2015; Soenksen et al. 2018). Furthermore, devices relying on active perfusion are equipped with extra instruments (e.g., pressure controls, sensors) and use either connective tubing or stiff monolithic design material that might impact the cell culture. However, media flow actuation with tubing or a monolithic design are so far the only approaches to interconnect individual culture chips. The tunable flow enables the control and circulation of media with secreted molecules by perfusing the entire system with common medium which paves the way to engineer complex human physiology on chip (Renggli and Frey 2020). Passive perfusion through gravity does not use extra tubing and instruments but is transient in nature and prone to performance variation (e.g., fabrication error, use-induced stress, trapped air bubbles). In addition, closed passive perfused systems can affect the chemical distribution rates as the combination of high plastic exposure with lower fluidic exchange and a lack of headspace may accumulate chemicals, especially after repeated exposure (Kramer et al. 2015; Proença et al. 2021). Future experiments for both, active and passive perfused systems, should address the potentially affected chemical biokinetics to provide clarity on diffusion rates.

\section{Engineering human tissue functionality on chip}

In the last years, the work is progressing on new approach methodologies for human relevant biokinetic predictions that move away from animal experimentation towards in silico and novel cell culture technologies (Punt et al. 2020). The use of animal data in human risk assessment raises concerns as animal tissue physiology does not always recapitulate human tissue physiology. In contrast, some static in vitro models with human cells may not represent the sensitive cellular microenvironment required for physiologically relevant simulations. OoC technology in combination with advance human cell models potentially offers a promising alternative to improve in vitro experiments by introducing biological functions, such as microfluidic shear stress and a 3D microenvironment. Despite the great promises of OoC, examples of successful application of OoC for NGRA are scarce due to cost, throughput, general OoC availability and cell culture challenges (Rusyn and Roth 2021; Low et al. 2021).

Next, we will discuss the engineering of a controlled 3D environment and three key human organ tissue systems in the culture compartments. We will elaborate on skin, intestine and liver models that are equivalent to at least the smallest functional unit of each organ (Ronaldson-Bouchard and Vunjak-Novakovic 2018; Jensen and Teng 2020). There are two critical factors which need to be addressed while engineering a tissue with organ-specific function on chip for a NGRA: (1) the establishment of a 3D architecture in the culture compartments and (2) the choice of cell line. In this section we discuss the significance of the above two factors and how they affect the functional capacity of the recreated tissue.

Single cells type monolayers might underrepresent the functional complexity as exhibited in the in vivo environment; however, a shift can be observed to improve the culture environment through the implementation of new approach methodologies (Punt et al. 2020). One new in vitro approach includes 3D cell culturing to recreate an anatomical architecture of a tissue of interest. Several studies have shown that upon recreating a 3D architecture, the cultured cells have improved characteristics in morphology, viability, differentiation, metabolic capacity as well as transporter and gene expression levels (Duval et al. 2017; Curto et al. 2017; Theobald et al. 2018; Lembong et al. 2018; Lee and Jun 2019; Jensen and Teng 2020). Two directions can be observed in recreating 3D architectures in OoCs. First, scaffold free techniques such as hanging drops, magnetic levitation and spheroid microplates with ultra-low attachment coating enable the cells to freely grow prior to seeding in OoCs. This technique is especially applicable for open accessible culture compartments as this layout allows direct seeding of bigger aggregates as demonstrated for liver spheroids (Lasli et al. 2019; Jang et al. 2019a; Kostrzewski et al. 2020; Tao et al. 2021). Second, scaffold-based techniques which use hard material-based polymers or hydrogel supports that mimic the extra cellular matrix (ECM) and enables the cells to properly attach and differentiate (Jensen and Teng 2020). The ECM biomaterial can be tumour cell-derived (e.g., collagen, Matrigel), purified protein, polysaccharide (e.g., collagens, alginate, bacterial cellulose) or produced synthetically (e.g., polyethylene glycol). Notably, all biomaterial will impact the intracellular signalling as well as the chemical distribution in the cell system (Gjorevski and Lutolf 2017; Hinman et al. 2020). Especially OoC have very particular chemical distribution processes that need to be addressed for better translatability, as reviewed by Proença et al. (2021). The review concludes that chemical distribution simulations are important for the validation, as part of chemical hazard identification (Proença et al. 2021). Furthermore, scaffoldfree and scaffolded techniques exploit the self-assembling 
capacity of cells. Different organ systems require specific 3D scaffolds, and cell types to allow for targeted functional tissue applications on chip and, therefore, require unique microfabrication techniques (Duval et al. 2017). Recent advanced in microfabrication techniques such as $3 \mathrm{D}$ printing offer a higher potential to recreate a controlled and reproducible 3D architecture (Zhao et al. 2019).

\section{Creating the best biology on chip}

Selecting the cell source is a critical aspect to consider for the engineering of a functional, scalable and reproducible organ tissue equivalent (Renggli and Frey 2020). The type of human cells to use largely depends on the emulation of the desired physiological function along with the cell type availability, cultivability, time line of the study, budget and availability of established protocols. Immortalized cell lines, primary cell cultures and derivatives of adult or induced pluripotent stem cells are classes of cells that can be utilized for tissue recreation. Advantages and limitations vary depending on the target organ and importantly on the research question.

Cell lines are widely used in toxicological proof-of-concept studies, because they are robust, easy to culture, wellcharacterized, affordable and highly proliferative. However, cancerous cell lines often exhibit significant genotypical and phenotypical abnormalities such as lack of metabolic capacity in terms of CYP450 gene expression and other metabolic enzymes, as well as lack of expression of protein transporters, potentially limiting their ability to reproduce physiological cell behaviour (Gillet et al. 2013).

In contrast to cell line-based models, primary cell cultures obtained from fresh tissue are considered a gold standard for in vitro models, because they resemble the in vivo cells the most. Primary cultures of certain cell types consist of a heterogenous cell population at various stages of differentiation and maturation (Verma et al. 2020). Once the cells are terminally differentiated, they may attach and remain viable in culture but will not proliferate anymore and nearly instantly dedifferentiate. The limited proliferative capacity is termed as replicative senescence, causing the major disadvantage of using primary cells in OoC (Cristofalo et al. 2004). Primary cell lines inherit the donor genotype that enables investigation of specific features of vulnerable groups but is a limitation for the generic assessment of molecular pathways and metabolism broader populations (Castell et al. 2006; Ertel et al. 2006).

The use of stem cell-derived cell culture models is gaining pace in toxicological research and continues to advance together with microfluidic culturing. Most stem cell-derived models in $\mathrm{OoC}$ are based on induced pluripotent stem cells (iPSC) as the microfluidic devices can direct differentiation (Yaqing Wang et al. 2018a, b; Ramme et al. 2019; Naumovska et al. 2020). The major iPSC-stem cell advantage is the usual normal karyotype and their derivation from human material, such as from biopsies, blood draws and urine. Upon reprogramming the derived human material, the stem cells may be selectively differentiated into multiple tissue specific-cell lineages, creating a replenishable source of cells (Wnorowski et al. 2019). Same as primary cells, iPSCs inhere the donor genotype which contributes to experimental variability and affect reproducibility of experiments. The genotypic and phenotypic differences make them on one hand ideal to study chemical responses for susceptible groups, whereas it might complicate mode of action studies for broader populations. Nevertheless, stem cells are in demand for NGRA studies, leading to a rapid development of culture protocols to overcome the largely fetal-like phenotype (Bulutoglu et al. 2020). The major challenge is the establishment of a robust and reproducible approach to maintain, differentiate and mature iPSC cell lines in vitro. Importantly, recent work by the groups of Bulutoglu and Sakolish raise confidence in lab-to-lab comparable and primary cell-like performing iPSC-derived hepatocytes in OoC (Bulutoglu et al. 2020; Sakolish et al. 2021). Notably, also direct on-chip culturing techniques were performed using iPSC-derived intestinal organoids. The derived cells exhibited organ-specific function in a quicker and resourceefficient manner (Naumovska et al. 2020). Despite current obstacles, stem cell culturing is expected to synergistically advance with OoC technology towards more robust human physiological models (Low et al. 2021).

\section{Advancing skin, intestine and liver tissue cultures on chip for next-generation risk assessment}

In this section we highlight promising advances for in vitro tissue culturing approaches that resulted in show case models. To do so, we focus on two important biological barriers, the skin and the gastrointestinal epithelium as important barriers for chemicals. In addition, we include liver-on-achip models as liver is the main metabolic active tissue and, therefore, highly relevant to include in NGRA. Finally, fluidically linked tissue combinations on-chip such as skin-liver and intestine-liver are reviewed as they form an innovative aspect for advancing and simulating kinetics for in silico modelling. 


\begin{tabular}{|c|c|c|c|c|}
\hline Reconstructed Huma & Human Skin & Pigmented HSE & Vascularized HSE & Immune competent HSE \\
\hline Epidermis (RHE) & Equivalent (HSE) & $\checkmark$ Keratinocytes & $\checkmark$ Keratinocytes & $\checkmark$ Keratinocytes \\
\hline$\checkmark$ Keratinocytes & $\begin{array}{l}\text { Keratinocytes } \\
\checkmark \text { Fibroblasts }\end{array}$ & $\begin{array}{l}\checkmark \text { Fibroblasts } \\
\text { Melanocytes }\end{array}$ & $\begin{array}{l}\checkmark \text { Fibroblasts } \\
\checkmark \text { Endothelial cells }\end{array}$ & $\begin{array}{c}\text { CFibroblasts } \\
\checkmark \text { LC// Dermal DC }\end{array}$ \\
\hline
\end{tabular}

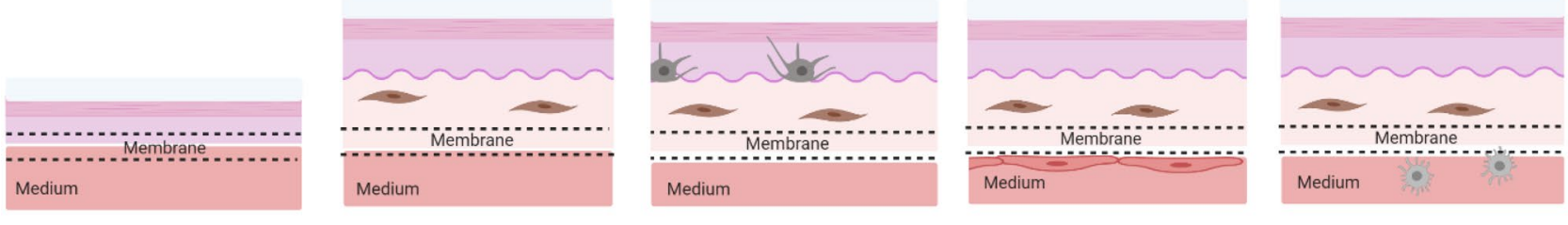

Complexity

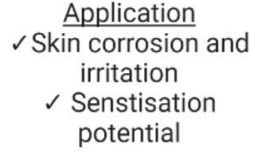

potential

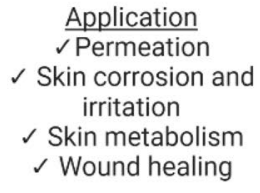

Application

Skin corrosion and

Skin metabolism

$\checkmark$ Wound healing

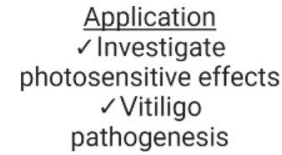

pathogenesis

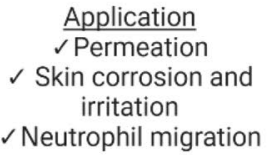

$\checkmark$ Neutrophil migration

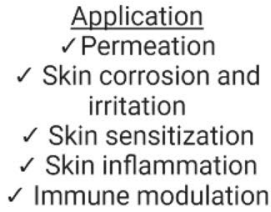

Fig. 2 Summary of selected 3D in vitro skin tissue models, depicted with increasing biological complexity and their research applicability and predictability for NGRA using an open access OoC device for air-liquid culturing

\section{Application of skin-on-a-chip in next-generation risk assessment of chemicals}

The skin is the largest organ of the human body and it is in direct contact with the outside environment. Thus, a healthy skin features barrier characteristics and thereby regulates the body temperature, retains moisture and protects against microbes and chemicals (Gauglitz and Schauber 2014). The human skin consists of three tissue layers-epidermis, dermis and subcutaneous layer. The stratum corneum is the epidermal top layer and is composed of dead skin cells and functions as the primary barrier. The epidermis is a dense and poorly vascularized region that mainly consists of keratinocytes (KC) with few pigment-producing dendritic cells (DC). Major immune cells in the epidermis are Langerhans cells (LCs) and dendritic epidermal T-cells (DETC). Below the epidermis lies the dermis layer which consists of a highly vascularized fibrotic layer which is low in cell density but rich in collagen and elastin fibres. Fibroblasts are the major cell type alongside with scattered immune cells. Finally, the deepest layer is the subcutaneous layer of fat that supplies nutrients to the outer layers. The epidermis and dermis play a major role in absorption, distribution, metabolism of xenobiotics as well as generate an immune response against xenobiotics. Therefore, these two layers are in focus for recreating better human relevant skin-tissue models (Chong et al. 2013). Within the NGRA toolbox for skin-contact materials, better skin models find value in the risk assessment of traditional endpoints, such as irritation, corrosion, phototoxicity, skin sensitization, as well as understanding and improving exposure estimations, stress pathways and metabolism (Gilmour et al. 2020; Baltazar et al. 2020).

Current skin research relies on the use of ex vivo mimetic models as gold standard but their use is not always possible due to ethical concerns, regulatory issues and variability, because samples are usually obtained from different anatomical sites (Moniz et al. 2020). Hence, engineered human skin tissues have been widely adopted for assessment of local toxicity in the skin. Notably, this resulted in harmonised in vitro testing by the newly adopted OECD testing guidelines which now involve human-based in vitro skin tissue models for chemical evaluation ( $\mathrm{Ng}$ and Yeong 2019; OECD 2021a, b, c). To evaluate the safety of chemicals, an in vitro 3D skin tissue can be either readily purchased or created by layering cell sheets. Then, these skin tissue models can be cultured dynamically in an open-top OoC device to be consequently lifted for creating an air-liquid interface (ALI) on the cell layer, as this forms the stratum corneum layer of the epidermis. In the past decade, various skin tissue models with different levels of biological complexity have been developed with immortalized cell lines, primary cells and stem cells (see Fig. 2) (Kandarova and Hayden 2021).

The simplest in vitro skin model is the Reconstructed Human Epidermis (RHE, see Fig. 2; Table 1) consisting only of keratinocytes cultured on a collagen matrix at the air-liquid interface. Commercially manufactured RHE models, 


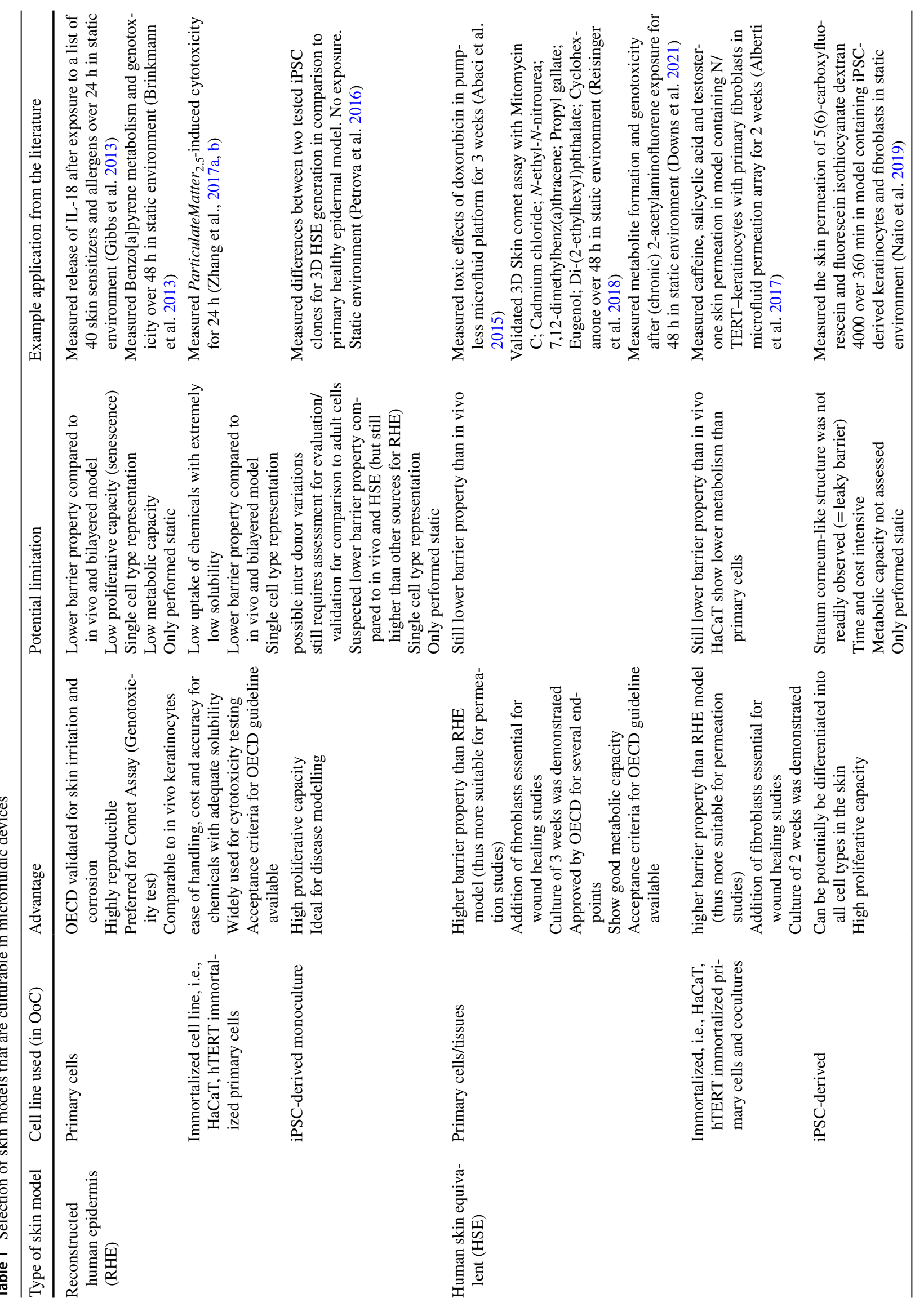




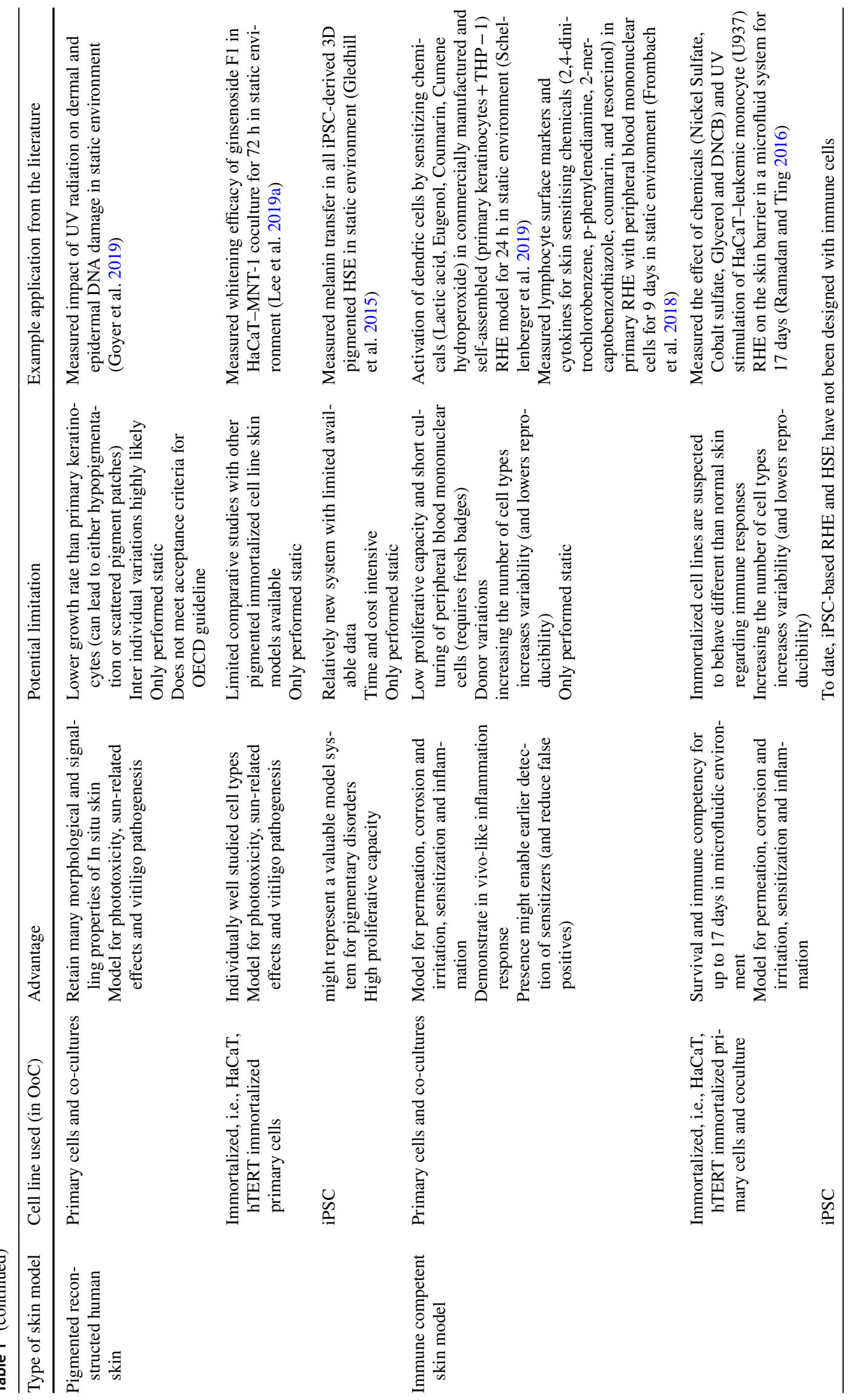




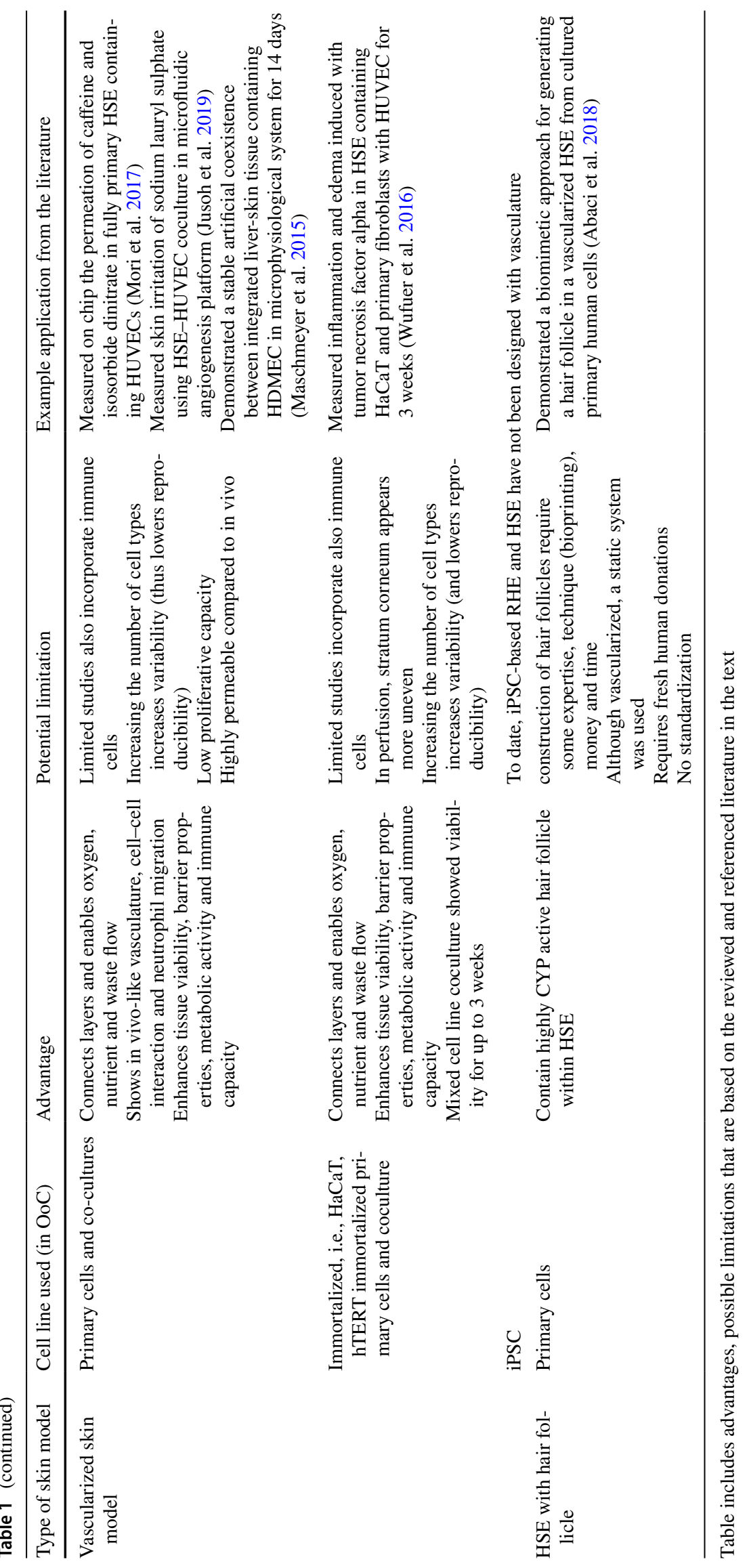


Episkin $^{\circledR}$, EpiDerm ${ }^{\mathrm{TM}}$, epiCS ${ }^{\circledR}$ and SkinEthic ${ }^{\mathrm{TM}}$, were first assessed as a predictive model for skin corrosion, but soon they were approved for determination of irritation potential marked through IL-1 $\alpha$ and IL-18 release (Gibbs et al. 2013; $\mathrm{Ng}$ and Yeong 2019). These RHE models are created with primary human keratinocytes (foreskin or mammary skin tissue) but other RHE models have also been established with immortalized human keratinocytes (HaCat) and iPSCderived skin cells (Petrova et al. 2016). All of them form a stratified epithelium after around 14 days of culturing under optimal conditions at the ALI (Mathes et al. 2014). RHE models are especially acknowledged for their reproducibility but they do not meet the requirement for permeation studies. Schäfer-Korting et al. (2006) showed that permeation of caffeine and testosterone using RHE is overestimated compared to the human epidermis. Therefore, RHE has limitedly utility for NGRA studies that require barrier function but may represent a useful tool for corrosion, irritation and skin sensitization potentials (Zhang et al. 2017a; Song et al. 2018; Teimouri et al. 2019; Mehling et al. 2019).

Another OoC model for skin with higher complexity than a RHE is a Human Skin Equivalent model (HSE, also: Full Thickness, bilayered reconstructed skin model). It consists of an epidermal and dermal compartment (see Fig. 2; Table 1). Commercially available HSE models, T-Skin ${ }^{\mathrm{TM}}$, Phenion ${ }^{\circledR}$ Full-Thickness Skin Model, EpiDermFT and Labskin, are derived from primary human cells and allow the investigation of skin metabolism, permeation and wound healing (van den Broek et al. 2017). Self-assembled models also exist with the use immortalized HaCaT and NTERT and iPSC-derived cells (Itoh et al. 2013; Reijnders et al. 2015). To generate a HSE, fibroblasts are integrated into a collagen I scaffold to create a dermal compartment. After coating with adhering collagen fibres, the keratinocytes are seeded on top to form a multilayer. HSE models are particularly suitable for xenobiotic metabolism studies, as the 3D matrix increases the metabolic capacity of the biotransformation enzymes in keratinocytes (Brinkmann et al. 2013). Additional to metabolism studies, HSE are also used for skin permeation studies of topically applied substances due to the increased barrier function compared to RHE (Alberti et al. 2017; Sriram et al. 2018; Schimek et al. 2018). The barrier properties of HSE models can be further improved by adding a hypodermis (subcutis) to advance the barrier function, as demonstrated by Schmidt et al. (2020). This thicker three-layered skin model reduced the permeation, exhibited suitability as an in vitro test system for irritating substances. Moreover, the model was proposed to exploit dermal deposition as a possible new endpoint for chemicals in the lipidrich hypodermis as there is a fundamental lack of studies for investigating the impact and effect on the pharmacokinetics (Turner and Balu-Iyer 2018; Schmidt et al. 2020). To study sun-associated adverse effects or vitiligo pathogenesis, HSE models are complemented with melanocytes (to treat pigmentation). Commercially manufactured models, MelanoDerm $^{\mathrm{TM}}$, epiCS ${ }^{\circledR}-\mathrm{M}$ and SkinEthic ${ }^{\mathrm{TM}}$ RHPE, make use of primary cells in co-culture with normal melanocytes (Lee et al. 2019a). A completely iPSC-derived 3D model has been created but was limited with unexpected low melanocyte count and viability (Gledhill et al. 2015). All before mentioned pigmented HSE have observed limitations, such as pigmentation flaws (complete absence of pigmentation or development of progressive pigmented spots), hypopigmentation or scattered pigmented spots which makes them limitedly recommendable for phototoxicity studies with UV-light exposure on-chip (Germain et al. 2018).

The addition of immune cells to reconstructed skin models allows the study of multicellular immune mechanism and reactions after cutaneous exposure that can potentially initiate allergic contact dermatitis (see Fig. 2; Table 1) (Thélu et al. 2020). The incorporation of the immortalized human acute myeloid leukaemia cell line, MUTZ-3, to derive phenotypically similar Langerhans cells (LC) is widely acknowledged to be valuable (Kosten et al. 2015; Bock et al. 2018). Such coculture models can be created in the lab or obtained from any commercial manufacturer. A RHE model can integrate LC progenitors which differentiate into antigen-presenting LC during tissue reconstruction (SkinEthic RHE 2020). To represent dermal DCs in immune-competent models, primary peripheral blood mononuclear cells (PBMC) and leukemic monocyte THP-1 cells are incorporated (Schellenberger et al. 2019). To date, none of the iPSC-derived skin model incorporates immune cells although iPSC can effectively differentiate into multiple functional lymphocyte lineages (Mathes et al. 2014; van den Broek et al. 2017; Thélu et al. 2020). Overall, all immune cell containing skin models still require more quantitatively defined criteria for reproduceable endpoint studies and are highly complex considering the performance of integrated more simplistic models (Thomas et al. 2019; Baltazar et al. 2020). Therefore, published literature on the application of fully immune competent skin-on-chip is scarce.

To physiologically connect skin tissue layers, the integration of endothelial cells (EC) such as primary derived human umbilical vein endothelial cells (HUVECs), human dermal microvascular EC (HDMEC) or iPSC derived EC are essential. The introduction of blood vessels in the dermis on-chip to simulate the microvasculature demonstrated an enhanced tissue viability, barrier properties, metabolic activity and immune capacity (Materne et al. 2015; Mori et al. 2017). A recent study by Kwak et al. (2020) using a primary cell derived vascular skin tissue on chip, mimicked the neutrophil migration after treatment with sodium lauryl sulphate and, therefore, demonstrated the added value of perfused vascularized models for immune studies. Overall, we conclude the vascularisation of skin tissues in OoC not 
only enhances functional results compared to static skin equivalents but also allows to study diffusion of chemicals and skin permeability on-chip. Introducing a microvasculature on-chip with good vascular permeability properties could lead to a promising tool in the NGRA toolbox and a platform for higher tier testing to replace the use of ex vivo and animal models (Risueño et al. 2021).

\section{Application of intestine-on-a-chip in next-generation risk assessment of chemicals}

The intestinal system accounts for the nutrient absorption and represents the first barrier of defence to keep harmful agents out of the body and prevent pathogens from entering via the diet. The small intestinal epithelium is characterized by the mucosa that contains circular folds and a dense array of villi to increase the available surface for nutrient uptake from the intestinal lumen. The intestinal mucosa can be divided into three layers, the muscularis mucosae (stroma), the highly vascularized lamina propria and a simple columnar ranged epithelium (Dutton et al. 2019). The small intestinal epithelium primarily consists of enterocytes with absorptive microvilli ( $>70 \%$ ), along with scattered mucus-secreting goblet cells ( 7\%); Paneth cells (5\%); stem cells, tuft cells and enteroendocrine cells (together $2 \%$ ) and covered by a firm layer of glycoprotein mucin (Rao and Wang 2010).

Furthermore, the gut epithelium is characterized by the tight junctional complex consisting of tight junctions and adherent junctions that maintain the barrier properties (Balda and Matter 2008; Sharma et al. 2010). Adding to the barrier property of the intestine, secreted mucus also functions as a stable ecological niche for the residing microbiome to exert enteric defence and food fermentation and breakdown, as well as bile acid metabolization (Liévin-Le Moal and Servin 2006). Moreover, the mucosal epithelium, especially through the M-cells, forms a functional unit with the inherent immune system through the lamina propria which samples luminal material to subsequently present antigens to the dendritic cells (Mestecky et al. 2015; Johansson and Hansson 2016). A protected niche is provided by crypts which are short tubular invaginations. The base of the crypts contain the intestinal stem cells neighboured by Paneth cells which release secretory granules in response to harmful bacteria, lipopolysaccharides (LPS) and cholinergic stimulation to induce an immune reaction (Ganz 2000).

Within the framework of NGRA, OoC intestinal models can be employed as part of the general toolbox to assess gutrelated in vitro endpoints focussed on the effect of chemicals on the barrier integrity and interaction of chemicals with the residing microbiome and the local immune system. In addition, OoC intestinal systems can be utilized to obtain data at higher tier targeted testing such as metabolism prediction, binding to proteins and DNA and formation of possible reactive oxygen species. Hence, the development of robust gut-on-chip models may allow the dynamic coculture of human intestinal epithelium cells to closely mimic and tightly control the interaction with microbiota, simulate oral absorption in interplay with physiological and biochemical processes and understand toxicity in the gut tissue.

Single intestinal cell type monolayers grown in a static environment have shown to be powerful in vitro models, yet they are limited in the emulation of complex in vivo cell tissue functionality (Costa and Ahluwalia 2019). Therefore, it is important to design human small intestinal tissue models with higher physiological relevance. Here, we will discuss different functional intestinal microtissue models that use membranes, flat or villi-like 3D ECM or other scaffolds in open- and closed accessible OoC devices. Figure 3 and Table 2 describe some of the advanced models that are used for NGRA. These models mostly contain immortalized cells or organoids as it has been technically challenging to culture single primary human intestinal epithelial cells separated from supportive cells (Madden et al. 2018). Therefore, immortalized cell lines and intestinal 3D organoid cultures derived from either intestinal crypts containing endogenous intestinal cells or iPSCs are predominantly used in studies. However, it must be noted that organoids are limited in their lack of supporting cell and tissue types (e.g., endothelial and immune cells) and their closed lumen when cultured within surrounding ECM (Bein et al. 2018).

The simplest in vitro model consists of a columnar enterocyte epithelium which may be cultured with the support of a biological 3D scaffold at the air liquid interface or submerged in the medium. Such a simple model is suitable for intestinal absorption and transport studies as demonstrated in multiple published studies using Caco-2 cells (see Table 2). Caco-2 are considered the gold-standard for investigation of intestinal absorption and transport because of their robustness, well-developed microvilli, increased cytoskeleton expression and tight junctional complexes compared to primary cells. This results in a barrier model with a low permeability for chemicals (Artursson and Borchardt 1997; Hilgendorf et al. 2000). In contrast, biopsyderived primary human intestinal cells that were separated from supportive muscle cells may show impaired function and viability and are, therefore, not suitable for use in invitro intestine models. Stem cell derived models have been limitedly exploited for chemical absorption and transport studies (Madden et al. 2018). Transport studies comparing transwells and microfluidic-perfused cultured Caco-2 tissues, have been performed to study 17 lipophilic dioxin congeners and to compare the transport of the highly permeable compounds, such as antipyrine, ketoprofen and digoxin. 


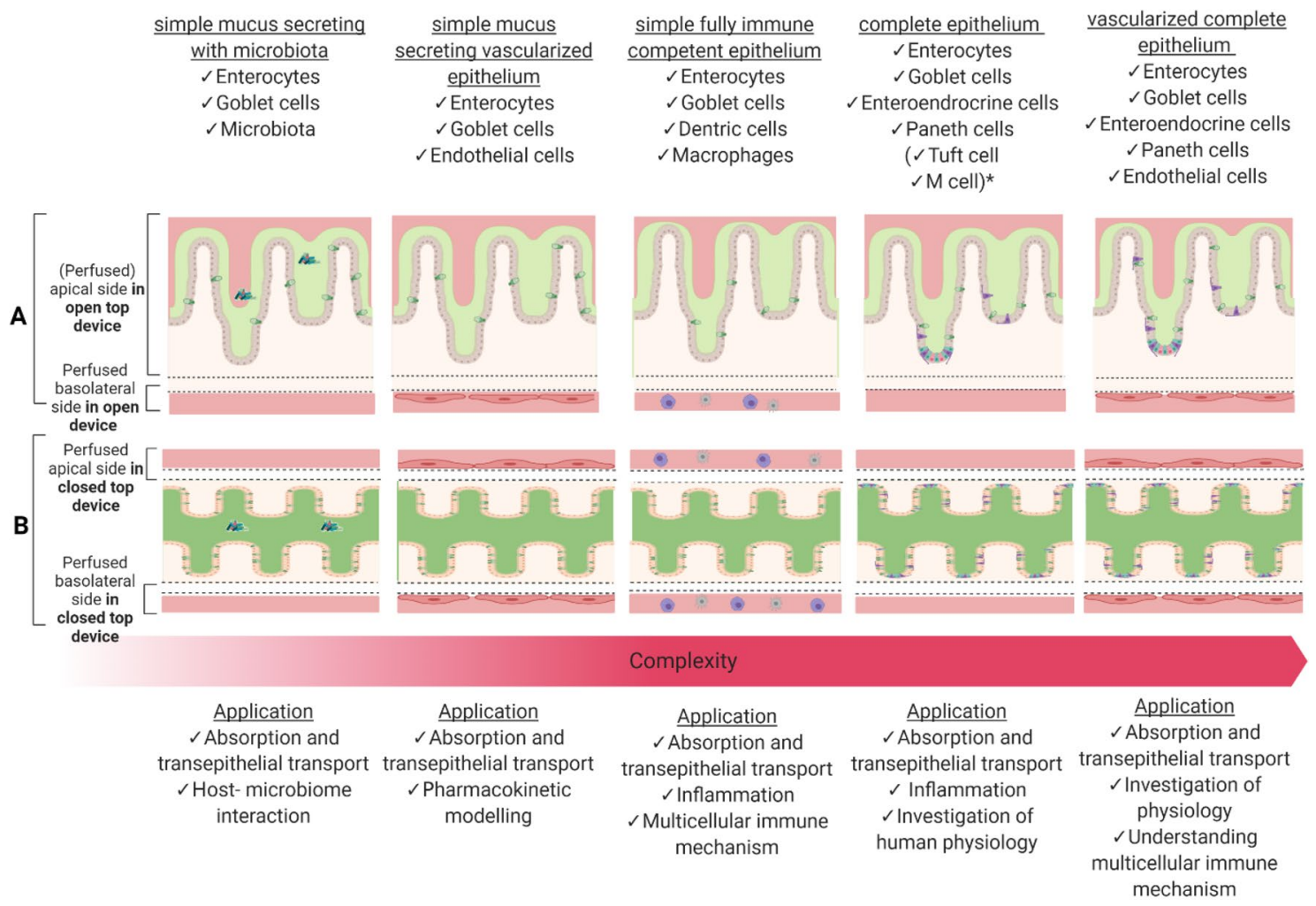

Fig. 3 Summary of 3D intestinal tissue models with increasing complexity and their research applicability and predictability for NGRA. The figure depicts two culture designs: A only one bottom membrane (top: applicable for cultures using open-accessible layout $\mathrm{OoC}$ or two channel closed layout $\mathrm{OoC}$ ) and $\mathbf{B}$ three channel closed with perfusion from both sides. (bottom) *only in primary cell cultures
According to Kulthong et al., the obtained transport values of the highly permeable chemicals were in line with the compound Biopharmaceuticals Classification System, demonstrating the value of dynamically cultured Caco-2 tissues (Kulthong et al. 2018, 2020). The simple columnarlike epithelium can be expanded by coculturing Caco- 2 cells with mucus secreting HT29-MTX goblet cells. A study by Santbergen et al. (2020) successfully coupled a dynamic cultured Caco-2/HT29-MTX model to a chip-based liquid chromatography mass spectrometry for investigation of oral bioavailability of ergotamine. In a different study, in attempt to mimic the lamina propria, De Gregorio et al. (2020a, b) integrated first primary myofibroblasts into their intestinal model with caco-2/HT29-MTX cells cultured on an air-liquid interface. The in vitro model demonstrated an in vivo-like transepithelial resistance but has not been tested for chemical exposure (De Gregorio et al. 2020a, b). Notably, Caco-2 cells contain tighter tight junctions compared to in vivo observations and low levels of cytochrome P450 isoforms, especially CYP3A which is responsible for more than $50 \%$ of xenobiotic metabolism in the gut (Kohl 2008). Therefore, an improved Caco-2-based OoC model is needed to better emulate the human intestinal functionality. For instance the addition of mucus secreting HT29-MTX goblet can reduce the permeability and impact cytokine secretion, diffusion of hydrophilic compounds and facilitates adhesion modulation of added microbiome and bacterial components (Hilgendorf et al. 2000; Martínez-Maqueda et al. 2015). The addition of microbiome can serve as an integrative approach to demonstrate host-microbiome interaction in health and disease, such as through inflammation-inducing cytokines and endotoxins but also because of interactions in drug pharmacokinetics and nutrition metabolism (Kim et al. 2016; Jalili-Firoozinezhad et al. 2019; Xiang et al. 2020). However, as reviewed by Elzinga et al. (2019), potential limitations of this complex integrated system include low reproducibility of the (anaerobic) bacterial cultures, potential bacterial overgrowth and a hampered formation of main epithelial cells types and crypts in organoids (Kim et al. 2016; Shin et al. 2020).

A complete epithelium model based either on primary cells or derived from stem cells (see Fig. 3) could provide a holistic model to investigate chemical absorption, metabolism and might provide a tool to study the effect of chemicals. Cui et al. (2020) evaluated the commercial EpiIntestinal ${ }^{\mathrm{TM}}$ bioprinted primary microtissue successfully as an ADME tool. In a non-commercial and bioprinted model, Maschmeyer et al. (2015) used an ileum section biopsy to 


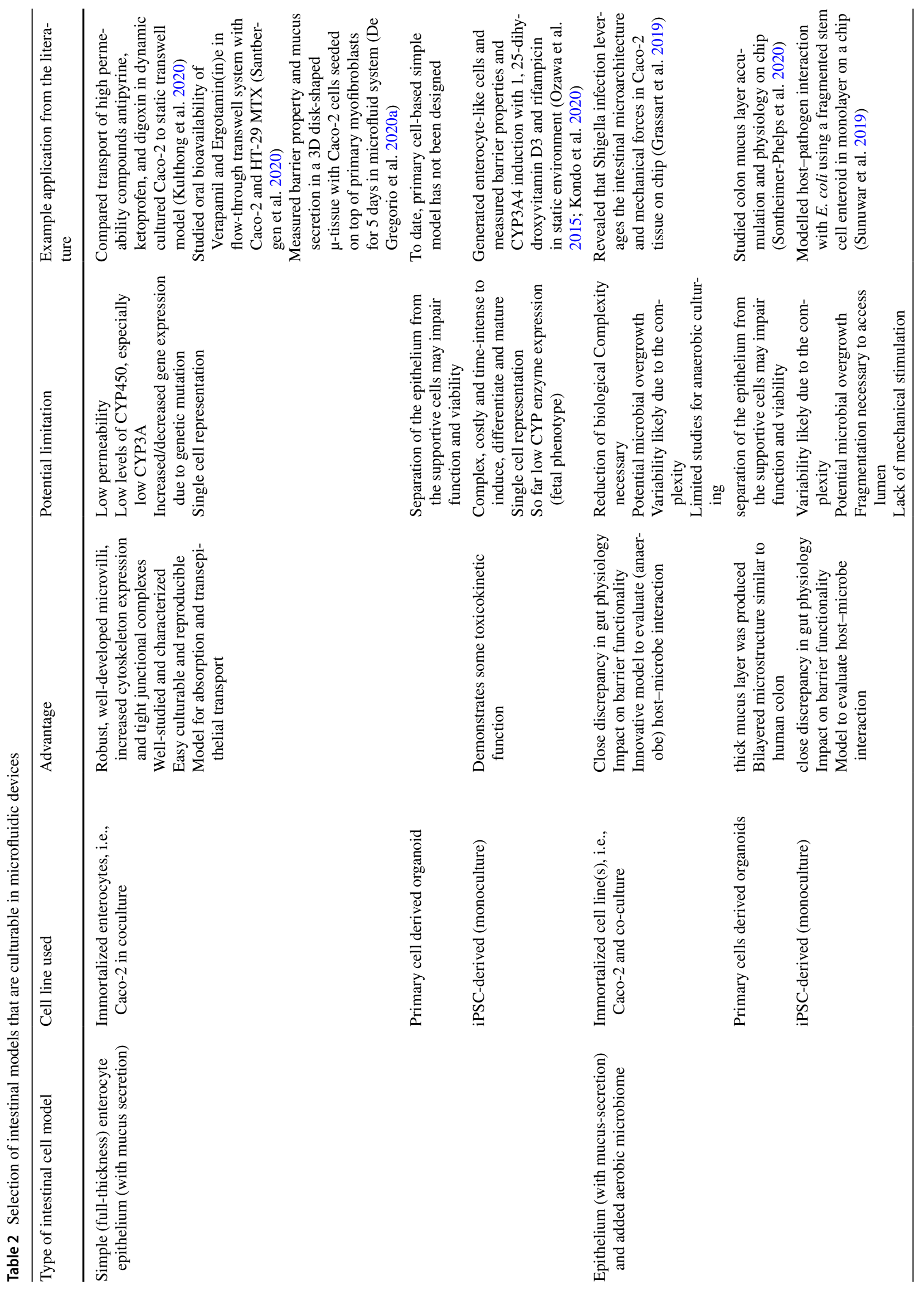




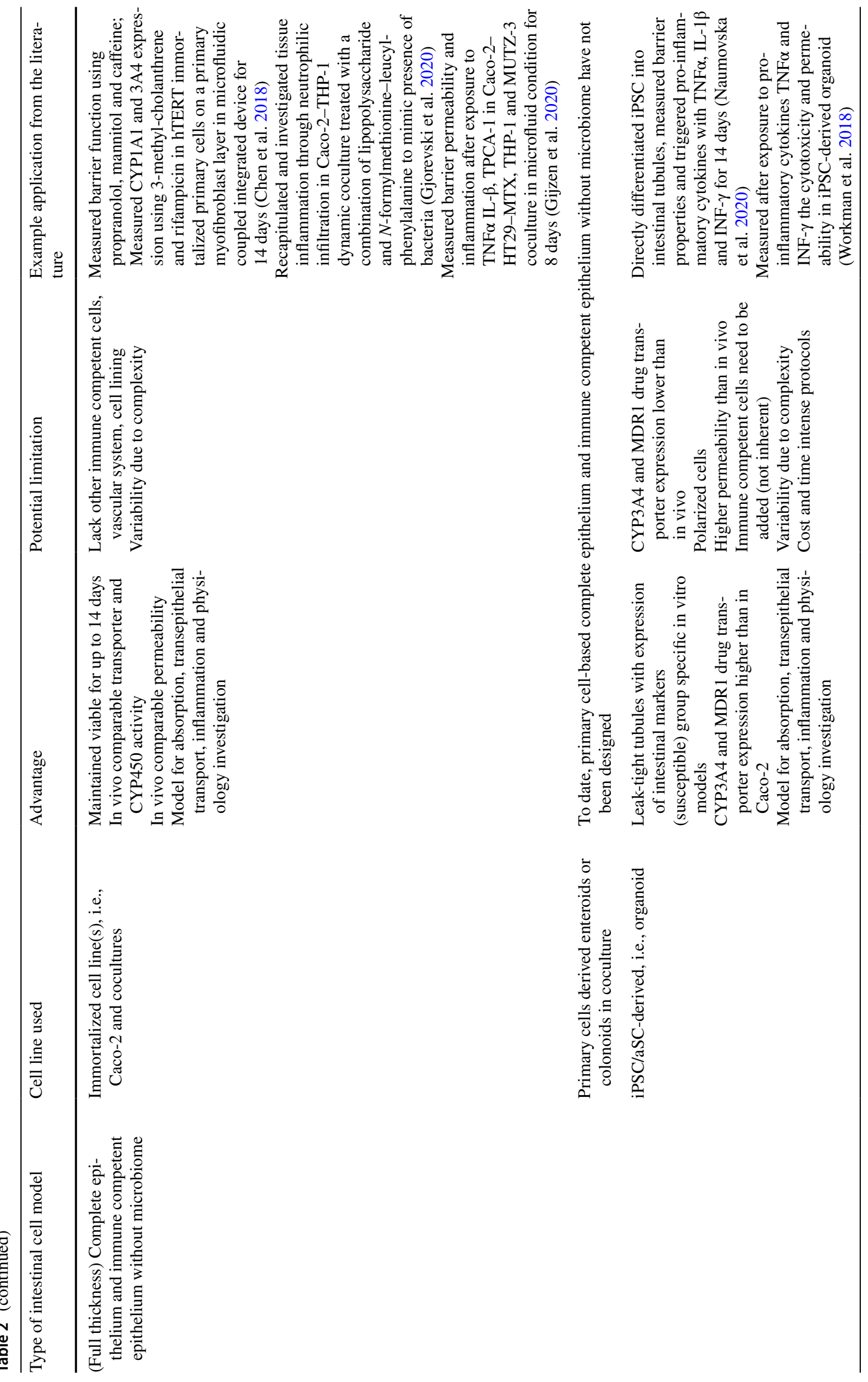




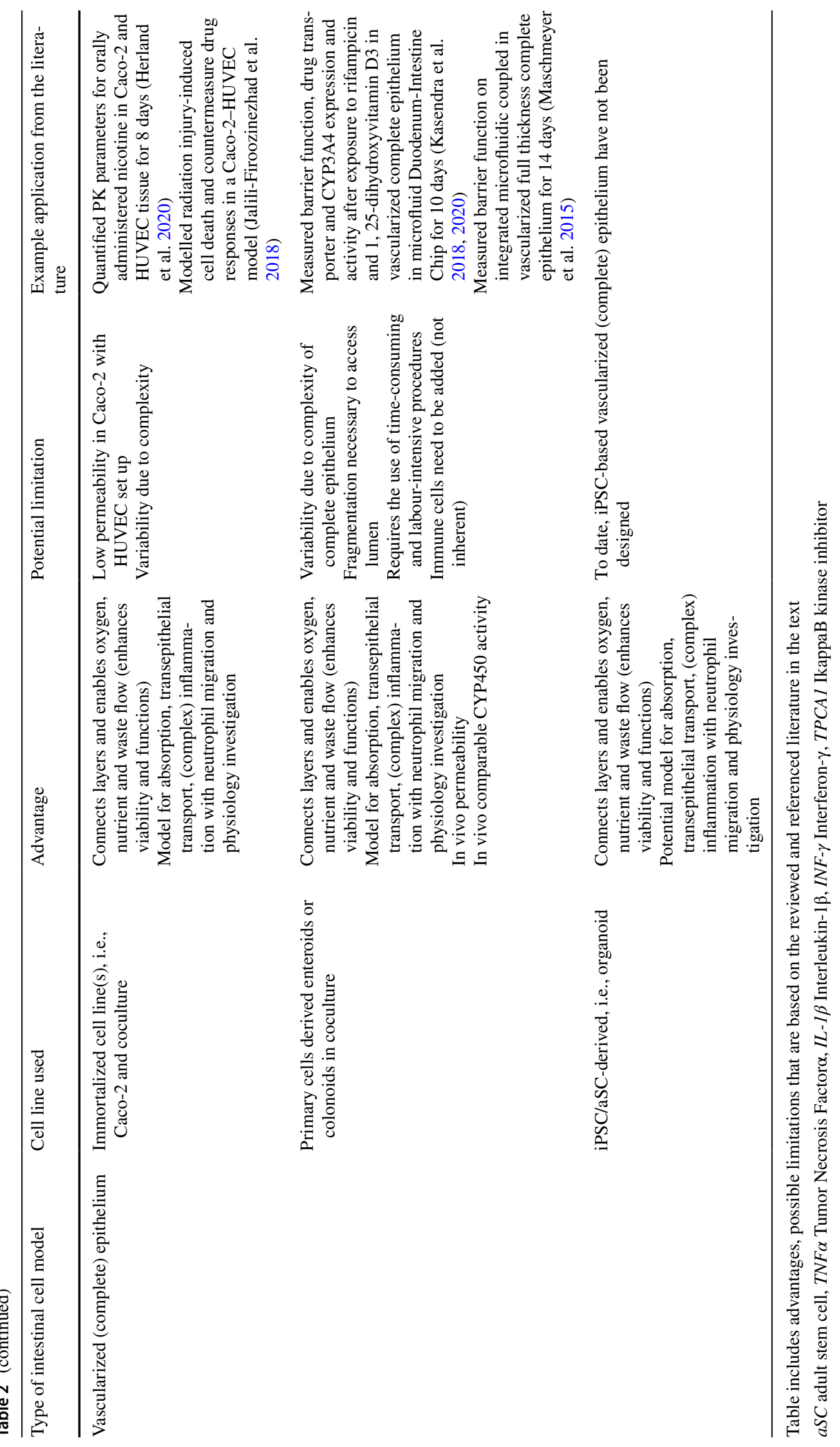


recreate a 3D full-thickness complete epithelium microtissue for an integrated system. In the microfluidic culture, the microtissue was viable and functional for 28 days and expressed physiologically relevant permeability and demonstrated in vivo-like drug transporter and CYP3A4 activity (Maschmeyer et al. 2015). Notably, OoC technology improves the differentiation of iPSC-derived cells into complete intestinal epithelium organoids on-chip, as demonstrated by Naumovska et al. (2020) and Beaurivage et al. (2020). Both studies presented a 3D model with an in vivo-like permeability and a higher drug transporter and CYP3A4 expression as compared to Caco-2 cells. Yet, one major limitation of primary cell and iPSC-derived tissues and organoids is the lack of standardized protocols for metrics and specification to recreate a reliable and predictable performance on-chip (Dutton et al. 2019). Another major limitation of organoids is the overall closed conformation, leading to a restricted apical-luminal access but also the lack of inherent immune competence. Several reports have been published about organoid cocultures with immune cell populations but it is important to acknowledge the challenge of adding additional components to an already complex system (Kim et al. 2020). An alternative is coculturing Caco-2 cells with HT29-MTX, THP-1 and MUTZ-3 as created by Gijzen et al. (2020) who measured barrier permeability and inflammation after exposure to TNF $\alpha$ IL- $\beta$, TPCA-1 in dynamic condition to study inflammatory response.

The intestinal models mentioned above can also be expanded by adding vascular cell into the lower membrane surface to introduce a biological barrier for transport studies, physiologically connect layers and to support tissue viability and functionality (Torras et al. 2018). A simple vascularized columnar-like enterocyte epithelium was recreated by Herland et al. (2020) using Caco-2 and HUVEC (see Fig. 3) on a fluidically-coupled organ chip. The endothelium-lined vascular channels in the model allowed for nutrient transport, waste removal and human pharmacokinetic modelling of caffeine. An advanced vitro tissue model by Seiler et al. (2020) used patient-derived human small intestinal cells on a myofibroblast layer with a recreated capillary network. The created tissue was characterized as a translatable ex vivo culture system and demonstrated angiogenic properties after exposure.

Although the studies show great advances in the intestine-on-a-chip field over the past decade, several challenges remain, such as the reproduction of all intestinal layers, especially with stem cell-derived cells. Moreover, intestine-on-a-chip lack a stable integration of a microbiome, and the provision of an intestine-specific environment (e.g., peristaltic, anaerobic etc.). These and more challenges must be overcome to achieve more physiologically relevant and standardized in vitro intestine models (Lee et al. 2019b).

\section{Application of liver-on-a-chip in next-generation risk assessment of chemicals}

The liver is a multifunction organ that coalesces all blood vessels coming from the intestinal tract into the portal vein. The portal vein branches in sinusoids that are comprised of highly permeable sinusoidal endothelial cells (LSECs) surrounded by hepatocytes which are also the main parenchymal cell in the liver (Davenport 2017). A small gap, known as the space of Disse, separates the LSECs from the hepatocytes. The sinusoids are inhabited by non-parenchymal cells such as the hepatic stellate cells (HSC) that help to maintain the ECM) and Kupffer cells which are the liver tissue specific macrophages. So-called bile canaliculi form small channels between the adjacent hepatocytes which secrete the bile. The secreted bile is collected in the bile ducts and transported to the intestine or gall bladder (Lu and Kacew 2002; Ishida 2020).

The liver is crucial organ to be included as an in vitro model as it is the major site for biomodifications of xenobiotics, i.e., Phase I (i.e., Cytochrome (CYP450)) and II (conjugation) metabolism) (Ishibashi et al. 2009). Within the general NGRA toolbox liver-on-chip adds value for the identification of liver specific endpoints, as well as to obtain data at higher tier testing in the ab initio approach application (Berggren et al. 2017). Xenobiotics that enter the liver can undergo biotransformation in which they may become toxicologically active, inactive, or reactive with endogenous macromolecules, potentially resulting in toxicity. Common mechanisms of hepatoxicity include the damage of macromolecules, mitochondrial dysfunction and oxidative stress, the activation of cell death-signalling pathways, modification of cell structure or function, and inflammation. All potentially xenobiotic-induced disturbances may contribute to several pathological conditions, such as steatosis, cholestasis, fibrosis and cirrhosis (McGill et al. 2015). Particular for the liver, the in vitro assessment of the end-points is complicated as the in vivo sinusoidal cell environment and functions are not homogenous along the portal-central vein axis. Depending on spatial location (zone) along this axis, an oxygen and metabolic enzyme gradient is created. Consequently, the present functional gradient in substrate metabolism, synthesis, storage and excretion affects the xenobiotic metabolism, resulting in a site-specific hepatic toxicity, altering gene expression and cell functions (Lu and Kacew 2002; McGinnity and Grime 2017; Soto-Gutierrez et al. 2017; Ahn et al. 2019; Ishida 2020).

Predictive liver in vitro models are highly demanded to evaluate biotransformation and mechanism-based hepatoxicity. Dynamic culturing holds a great promise to expand the predictive capacity by facilitating the emulation of 


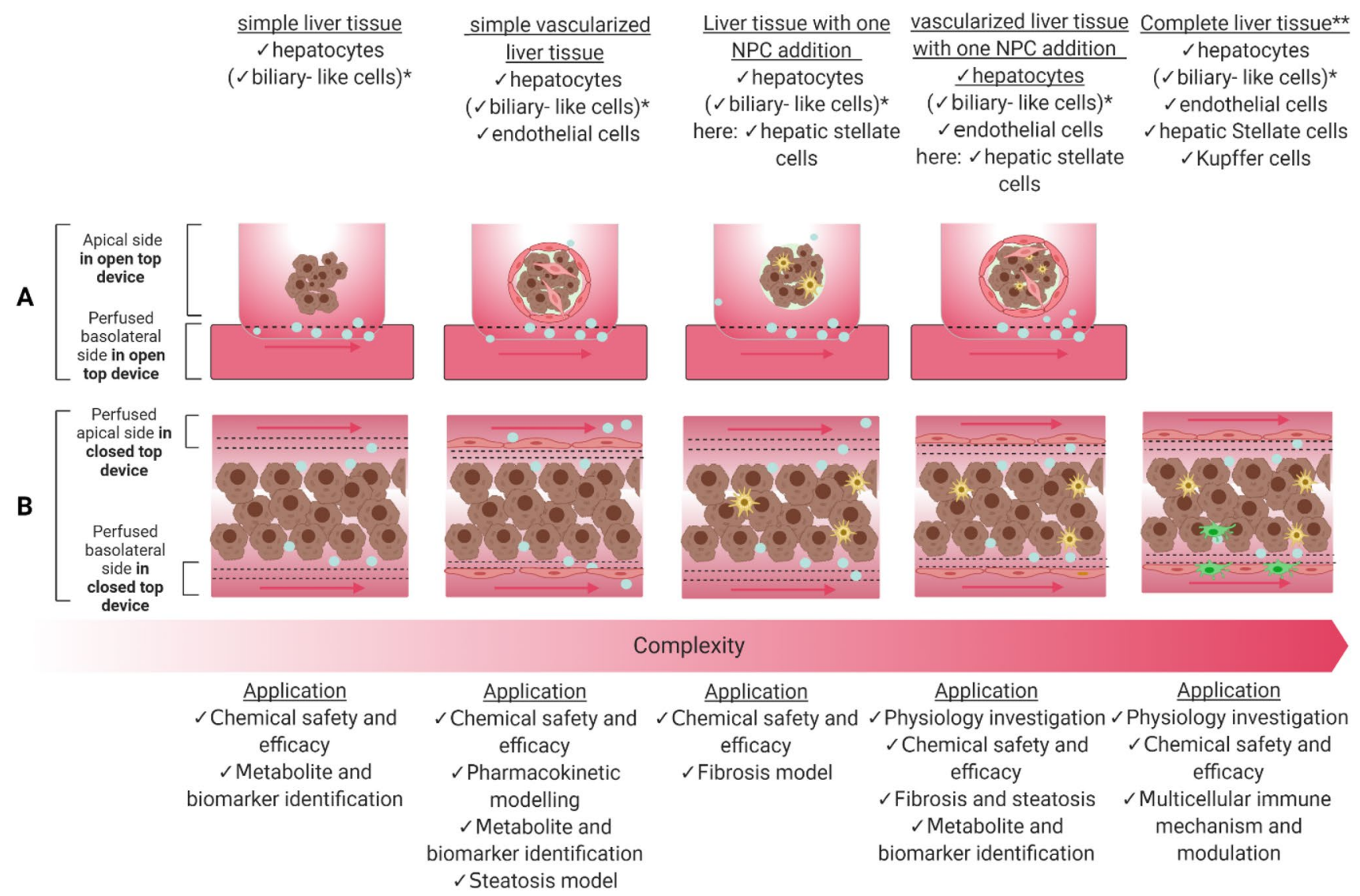

Fig. 4 Summary of 3D liver tissue models with increasing complexity and their application in NGRA. The figure depicts two tissue approaches, A only a bottom membrane (top; applicable for cultures

liver-specific functions and spatial gradient variation and to perform targeted testing and biokinetic refinements (Berggren et al. 2017; Kang et al. 2018; Ehrlich et al. 2019; Ahn et al. 2019). Figure 4 and Table 3 depict liver models with increasing biological complexity, cultured in different $\mathrm{OoC}$ layouts and containing differently originated cells. Notably, three liver tissue formats are frequently used in OoC: hydrogel scaffolded 3D tissues, pre-cultured spheroids and 2D monolayers.

Single cell type monolayers cultured on a coated microporous membrane are still a frequently used tissue format in OoC. Sandwich- and micropatterned (co)cultures are both metabolically competent and have proper localisation of basolateral and canalicular transporters with functional bile networks (Swift et al. 2010; Beckwitt et al. 2018). Recently, Duivenvoorde et al. (2021) cultured dynamically a 2D HepaRG sandwich culture and demonstrated successfully improved gene expression and biotransformation activity compared to a static culture. Azizgolshani et al. (2021) came to a similar result when measuring the CYP expression in real time with their high-throughput $\mathrm{OoC}$ platform using primary hepatocytes $(\mathrm{PHH})$ in 2D culture. Notably, sandwich using open-accessible devices) and $\mathbf{B}$ three channel closed-accessible designs with perfusion from both sides. (bottom) *only in HepaRG, primary cell cultures and iPSC **does not exist (yet) as spheroid

cultures are restricted by their flat histology for physiological-relevant coculture with non-parenchymal cells (NPC), whereas micropatterns may constrain the cell morphology (i.e., shape) and come partially with extra manufacturing costs and material concerns (D'Arcangelo and McGuigan 2015; Zhang et al. 2017b).

The recent $\mathrm{OoC}$ culture advances enables 3D spheroids models to remain viable for much longer period of time than conventional sandwich cultures, allowing for repeated exposure studies (Ramaiahgari and Ferguson 2019). Spheroids can be easily seeded and cultured in open-accessible OoC device (see Fig. 4 top) and generated with several techniques prior seeding, such as hanging drop, spinner flasks, cell culture on ultra-low attachment surfaces and scaffold-based micromolding (Ma et al. 2018). Larger aggregates exhibit limitations in mass transport for nutrients and oxygen diffusion easily causing a necrotic cell death inside the spheroid core due to impaired cell division, as well as heterogenous viability and function. A study in static condition by Bell et al. (2016) stated a high viability and functionality of self-assembling primary human hepatocytes (PHH) spheroidal aggregates but also difficulty to maintain a 


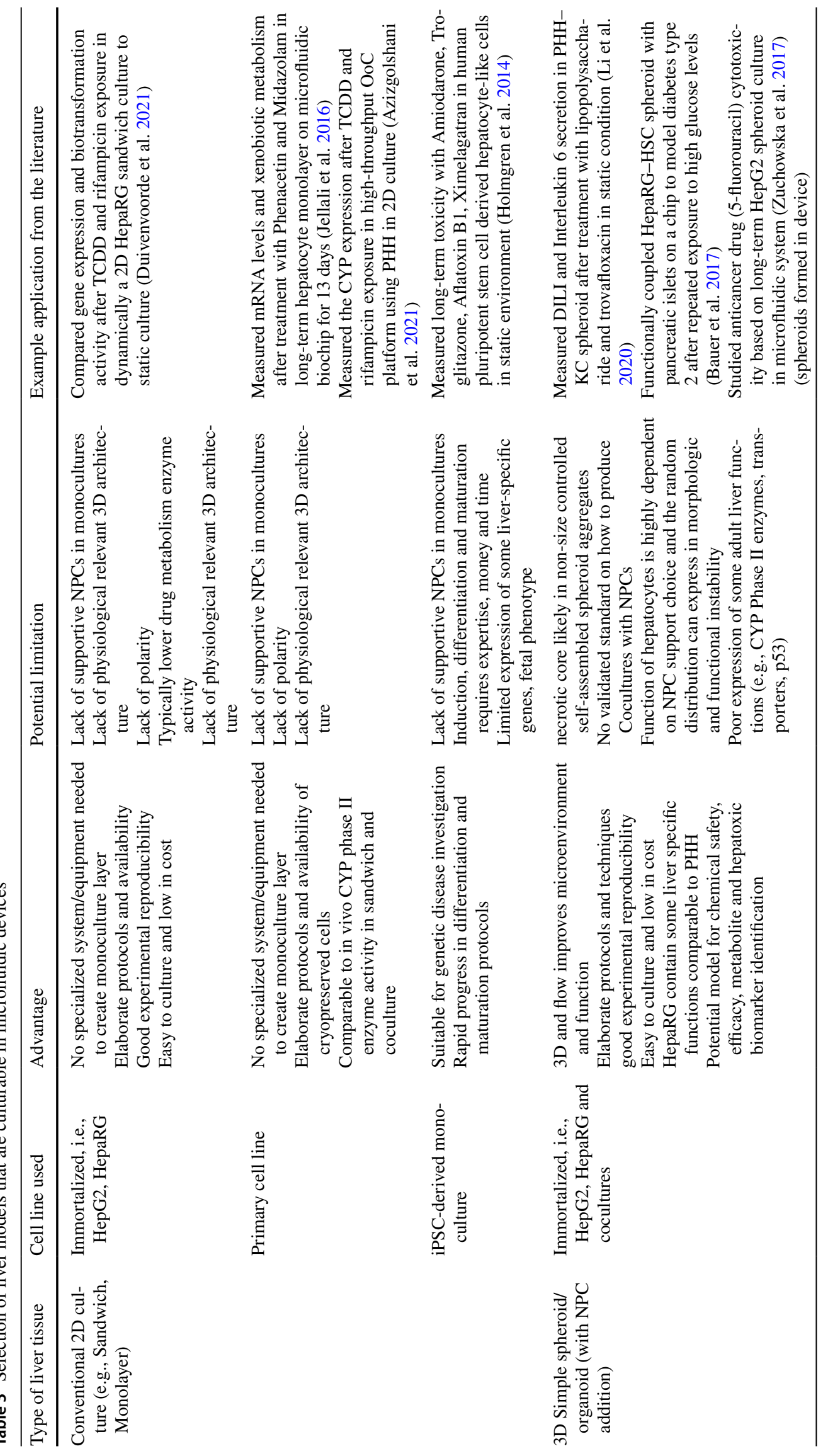




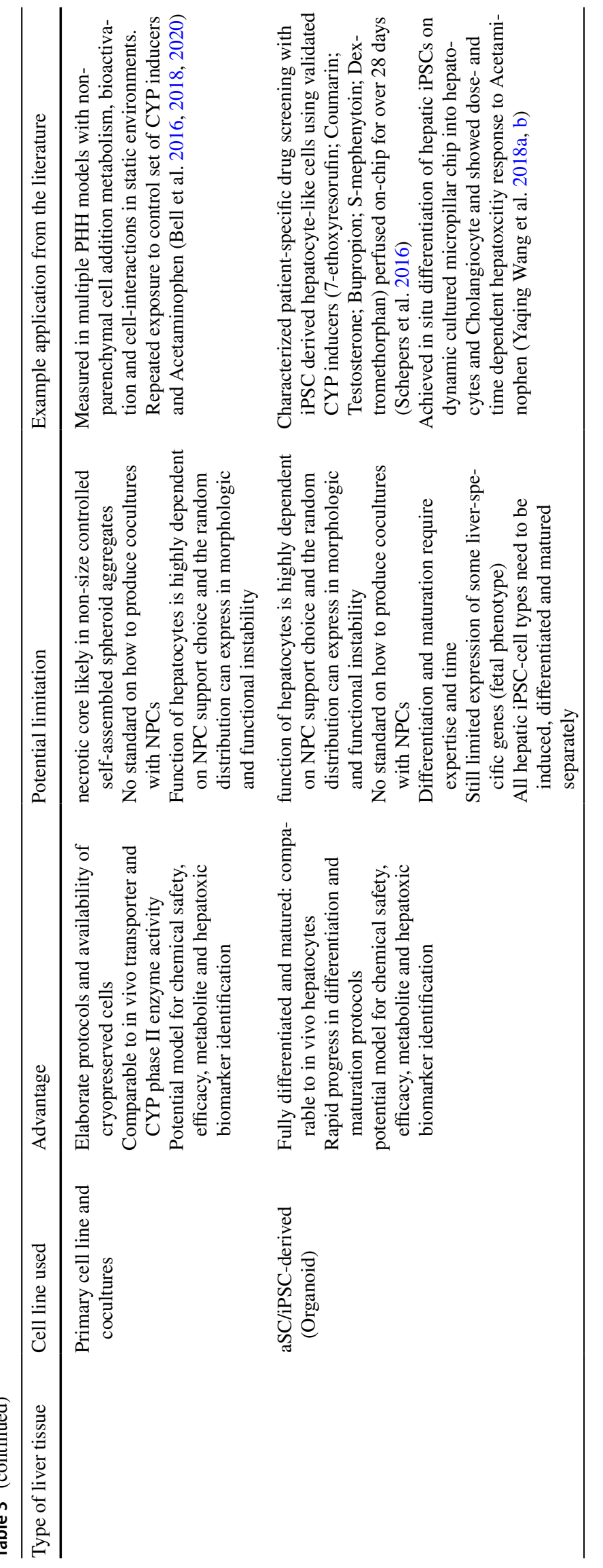




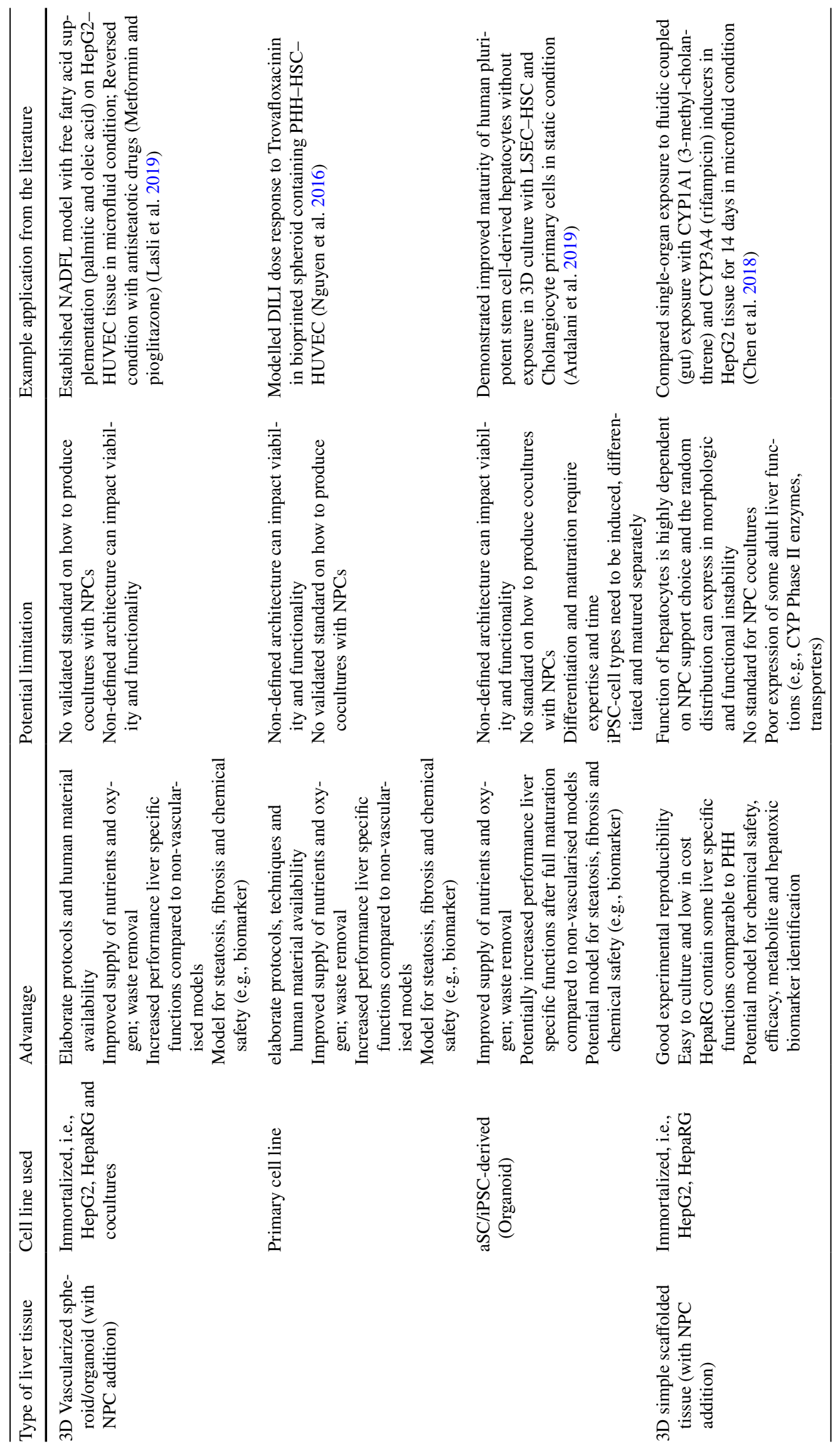




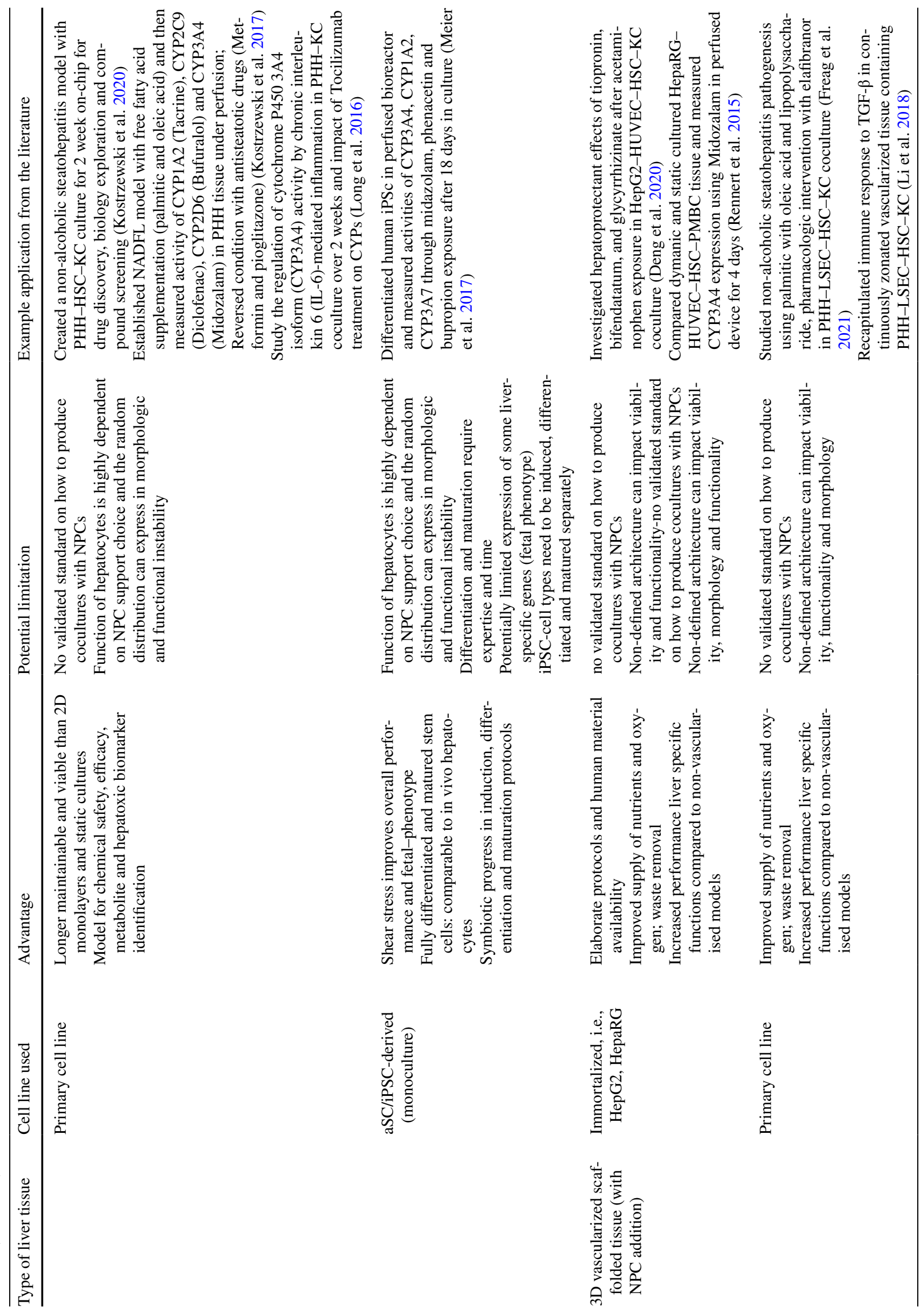




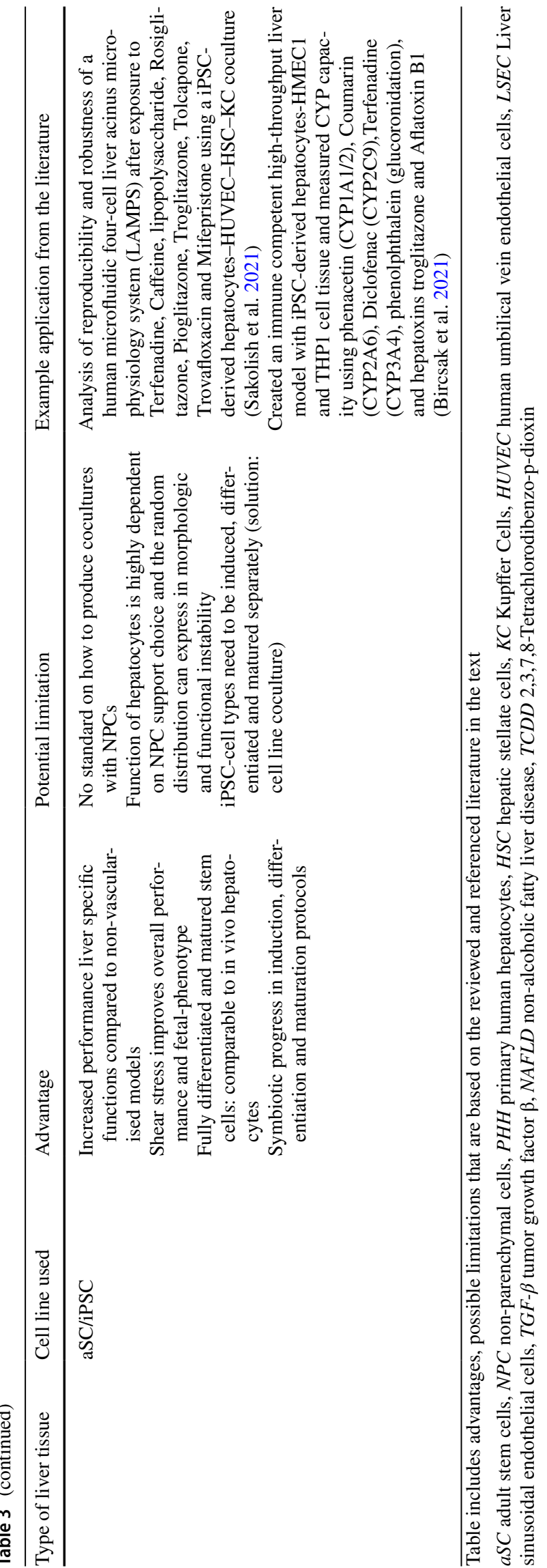

uniform size and cluster of cells in non-adhesive plates (Ma et al. 2018; Underhill and Khetani 2018). Plate-based and hydrogel micromolding and bioprinting address the limitation of spheroid size variability by directing the assembly. The iFlowPlate ${ }^{\mathrm{TM}}$ by Lin et al. (2021) currently offers an approach to produce scalable perfusable vascularized liver spheroids for $\mathrm{OoC}$ without bioprinting.

A simple iPSC-derived hepatocyte-like (HCL) organoid for an in-lab assembled OoC was established by Schepers et al. (2016) which exhibited genotypic CYP450 activity which could be maintained for 28 days. A big leap towards a more complex liver model was taken by Leite et al. (2016) and Maschmeyer et al. (2015) through the addition of primary human hepatic stellate cells to a primary human hepatocyte (PHH) culture in the TissUse OoC device. Maschmeyer tested the hepatic biotransformation by repeated troglitazone treatment, whereas Leite investigated chemical-induced HSC activation and fibrosis using Allyl alcohol and Methotrextate (Maschmeyer et al. 2015; Leite et al. 2016). In a different study, using a PHH-Kupffer cells coculture in static condition, $\mathrm{Li}$ et al. (2020) investigated the role of Kupffer cells in inflammation and drug-induced liver injury (DILI). The immune competent liver spheroid model demonstrated the importance of Kupffer cells in DILI by evaluating the signalling pathways after treatment with lipopolysaccharide and trovafloxacin. In another spheroid model by Lasli et al (2019), endothelial cells of primary origin were incorporated to form vascularized liver spheroids. These authors precultured in pyramid-shaped microwells HepG2 with HUVECs to size-select the self-assembled spheroids. After collection and culturing in microfluid condition, the spheroids showed a stable phenotype to model hepatic steatosis induced with palmitic and oleic acid. Another biologically complex model was developed by Ardalani et al. (2019), using iPSC-derived hepatocytes and endothelial cells with hepatic stellate cells and Cholangiocyte primary cells in static condition. The developed vascularized spheroid model showed that coculture with endothelial cells improve hepatic functionality, but the model still expressed fetal markers and immature functions compared to primary cells. Eventually, the authors conclude that the integration of the aggregates in $\mathrm{OoC}$ can potentially improve the liver model (Ardalani et al. 2019).

A final culturing format is the culturing of liver cells in a 3D scaffold on chip. For this, liver cells are mixed with scaffolding proteins $(\mathrm{ECM})$ to self-assemble a 3D structure within a closed OoC culture compartment. As to be seen on the bottom of Fig. 4, the cell-ECM culture mixture is separated by protective microporous membrane from the perfusion channels (Jang et al. 2019a, b). A simple liver tissue was created by Jang et al. (2019a, b), who differentiated HepaRG progenitor cells without dimethyl sulfoxide directly on chip. The study demonstrated the major advantage of 
this liver tissue type, the simplicity to study Phase I and II metabolism, transport and hepatoxicity. However, the limitation of this simplicity is the reduced biology due to the lack of supporting non parenchymal cells that might impact effects after chemical exposure. In the liver, endothelial cells represent the most abundant NPC and form the crucial permeable blood-parenchymal barrier. Vascularized liver tissue models may incorporate primary human endothelial cells such as LSEC, HUVECs or iPSC-EC into the (upper and) lower perfusion channel to recreate an in vivo-like permeable barrier. A simple vascularized tissue was established by Herland et al. (2020), containing a PHH-LSEC coculture that was incorporated into a multi-organ-chip. Within this system, this rather simple tissue could successfully mimic the first-pass-metabolism of nicotine and quantitatively predicted human pharmacokinetic parameters for in silico modelling. In pathological conditions, LSECs play a key role in the initiation and progression of chronic liver diseases in interplay with HSC and Kupffer cells (Poisson et al. 2017). HSC mediate the balance of inflammation, the tissue generation after DILI while also facilitating cell-cell communication between hepatocytes and endothelial cells, whereas Kupffer cells play a major role in inflammation and immune responses (Kasuya et al. 2011). Long et al. (2016) studied in a PHH-Kupffer cell coculture the regulation of cytochrome P450 3A4 isoform (CYP3A4) activity by chronic interleukin 6 (IL-6)-mediated inflammation over 2 weeks and the de-suppressed CYP3A4 activity of Tocilizumab exposure in presence of IL-6. The most complex liver tissue model that incorporates all four major liver cell types at in vivo ratios (here: Fig. 4 as complete liver tissue) was established by Vernetti et al. (2016) and called Liver Acinus MicroPhysiology System (LAMP). The focus of that study with the LAMP model was to measure CYP and UGT activity over 28 days in cells of primary source. Later, Li et al. (2018) recapitulated clinically relevant tissue responses for experimental modelling of liver physiology and (immune) diseases, as well as ADME/TOX using the same model. At this complexity the tissue might mimic elaborate (immune) diseases but becomes also more prone to variabilities, as no validated standards exist to engineer and scale these complex NPC cocultures for the characterization of key events in NGRA. However, Sakolish et al. (2021) showed that LAMPS can be a robust and reproducible in vitro liver model in dynamic culture. The improved model performance was in vivo-comparable when the tissue was seeded with either primary human hepatocytes or iPSCderived hepatocytes.

\section{Functional integration of tissue systems by fluidic coupling}

The next major step in OoC technology is the microfluidic functional coupling of individual organ-compartments to a multi-organ-chip (Sang Hun Lee and Jun 2019; Vernetti et al. 2017). Multi-organ-chip have great potential to improve the NGRA toolbox as the different incorporated organ tissues will affect the pharmacokinetic and pharmacodynamic properties of circulating chemicals. This novel but complex approach will facilitate the simulation of absorption (i.e., skin or intestine), subsequent first-pass metabolism and/or hepatic bioactivation, transport to the target-organ(s) (ADME) (see Table 4). Although the manufactured OoC devices differ in design for their mimicked function (i.e., air-liquid culturing), most platforms allow their tissue to be fluidically linked to enable dynamic tissue-tissue communication through the secreted soluble factors and extracellular vehicles (Ronaldson-Bouchard and Vunjak-Novakovic 2018; Wu et al. 2020). Depending on the culture set up, the tissue locations are fluidically connected with passive flow or active flow via a pump with tubing or a monolithic design

Table 4 Selection of studies using microfluidic coupling to co-organ culture with varying applications. Studies made use of different commercially available devices or self-assembled platforms and are focused on skin, gut and liver co-organ cultures

\begin{tabular}{|c|c|c|}
\hline Integrated tissues & Example application & References \\
\hline Skin-liver & $\begin{array}{l}\text { Integrated skin tissue into two-organ chip for permeation study with possibility to } \\
\text { extended model for in vitro substance testing including liver }\end{array}$ & $\begin{array}{l}\text { Schimek et al. (2018) } \\
\text { Tao et al. (2021) }\end{array}$ \\
\hline Intestine-liver & First-pass metabolism of ethanol & De Gregorio et al. (2020 b) \\
\hline Intestine-liver & Acetaminophen absorption and metabolism & Marin et al. (2019) \\
\hline Intestine-liver & Quantitative in vitro pharmacokinetic study & Tsamandouras et al. (2017) \\
\hline Intestine-liver-kidney & Quantitative prediction of human pharmacokinetic and toxicity & Herland et al. (2020) \\
\hline Intestine-liver-kidney & $\begin{array}{l}\text { Establishment of exposure-response relationship for pharmacodynamics and toxic- } \\
\text { ity }\end{array}$ & Maass et al. (2017) \\
\hline Intestine-liver-brain-kidney & Autologous induced pluripotent—stem cell derivation from same donor & Ramme et al. (2019) \\
\hline Skin-liver & $\begin{array}{l}\text { Characterization of application scenario-dependent pharmacokinetics and pharma- } \\
\text { codynamic properties of permethrin and hyperforin }\end{array}$ & Kühnl et al. (2021) \\
\hline Skin-heart-liver & Evaluation of topical drug delivery & Pires De Mello et al. (2020) \\
\hline
\end{tabular}


(Renggli and Frey 2020; Zhang et al. 2020). An alternative fluid exchange displays transferring fluids with an automated liquid-handling instrument between reservoirs. Multi-organchip offer undoubtedly a diverse spectrum of applications in NGRA and are expected to provide novel solutions in the field of New Approach Methodologies (Punt et al. 2020). Technical challenges that still need to find a solution include the development of a device that considers at the same time different organ flow patterns and functions (i.e., peristalsis, elongation, local pressure) whilst using an appropriate material (e.g., non-binding, biocompatible) but also facilitates long-term culture (e.g., decrease risk of contamination and trapped air bubbles) (Renggli and Frey 2020). Besides, current biological constraints range from an appropriate and physiological-relevant tissue scaling and stability, to a common medium composition for circulation (for coculture connection and feeding), as well as the selection and creation of assays to evaluate the culture tissues separately (Bovard and Sandoz 2019; Picollet-D'hahan et al. 2021). However, current multi-organ-chips can already emulate key aspects of an in vivo human environment and mimic organ-organ interaction and ADME processes which was previously only available through in vivo models. Therefore, more advances in device manufacturing, fit-for-purpose and validated assays and protocols is highly expected as multi-organ-chip system developers and users are gaining scientific experience (Marx 2020).

\section{Challenges and prospects for $\mathrm{OoC}$ technology and NGRA on-chip with skin, intestine and liver tissues}

Organ-on-chip is a rapidly evolving technology that offers versatile systems to mediate the formation of functional tissues and organs for different research applications (see Fig. 1). All reviewed commercially available devices offer significant technical advantages to culture and investigate biologically improved organ tissue models. Yet, there are clear needs and challenges that must still be addressed from the initial hardware development until the final user application as also pointed out by the organ-on-chip-indevelopment (ORCHID) initiative roadmap (Mastrangeli et al. 2019; Piergiovanni et al. 2021). Aligning with the ORCHID initiative, we conclude that the device specifications must be addressed first. This includes the search for the ideal (hybrid) materials for devices and scaffolds that can enable appropriate cell cultures with low chemical adsorption and absorption and biocompatibility. In addition, novel (hybrid) materials should be flexible to allow for physical strain to be included (i.e., stretchable membranes), while optical transparency should remain present for cell imaging (i.e., microscopy).
While a diversity of commercially available OoC devices exist, there is no ideal versatile hardware layout. Some of the devices have external dimensions that are comparable to routinely used labware which allows easier integration into routine lab practices. We recognize that different research questions, and specific tissues culturing demands (i.e., for skin, intestinal and liver tissues) require different $\mathrm{OoC}$ device designs. For the barrier skin open-accessible devices might be desirable for air liquid culturing, while for the intestine OoC models both open and closed configurations might be interesting. Open-accessible tissue compartments offer better access for pipetting, layering, air-liquid interfacing or space for bigger cell aggregates, whereas the flow can be less controlled. In contrast, closed culture compartment can mimic better mechanical forces such as flow and stretch and may allow anaerobic intestinal culture.

An important aspect of $\mathrm{OoC}$ devices is the current lack of versatile microfluidic perfusion in the devices. Flow can be actively induced through directly integrated and plug-in pumps or passively through gravity-drive. Passive perfusion enables flow without additional tubing, whereas devices using pumps allow for a more controlled induction of shear stress and facilitate fluidic connection to different organ tissues. Nevertheless, there are still technical challenges to face for the hardware that include a stable fluid connection without bubbles and sterility of tubing. While often addressed as a concern, chemical sorbing to the materials used have only limitedly been studied so far. Data and knowledge on the absorption of chemicals on to the fabrication material needed to ascertain the acceptance of OoC models as NGRA toolbox for the toxicological hazard characterization of chemicals.

Yet, OoC tissue models have already advanced the biology of human in vitro tissue culturing. The combination of both, 3D architecture and fluidic flow, has shown great impact on cellular characteristics such as on the morphology, viability, differentiation, metabolic and enzymatic capacity, as well as transporter and gene expression levels. These improvements strengthen the relevance of OoC technology as the advances have been observed with several cell lines and cell types. The next step towards creating advanced $3 \mathrm{D}$ cultures and incorporation of stem cell derived tissues on-chip for a future NGRA are promising but also show the need to standardise advanced organ tissue culturing for human health effect assessment.

For the skin tissue, models demonstrated that OoC offer an improved approach to assess the safety and efficacy of topically applied consumer products to assess endpoints, such as permeation, irritation and corrosion, phototoxicity, as well as skin sensitization and inflammation. For the investigation of these endpoints a range of different skin models were established and assessed ranging from single cell type model such as RHE to HSE with additional cell types and 
appendices (see Fig. 2). Specifically for skin-on-chip, the new adopted OECD guidelines for endpoint testing (OECD $2021 \mathrm{a}, \mathrm{b}, \mathrm{c})$ will gain importance to harmonise the assessment for chemical safety information.

For the dynamically cultured intestinal tissues an advanced understanding of the permeability, absorption and transport orally ingested compounds has been shown. The introduced in vitro intestinal tissues ranged in biological complexity, from a simple columnar-like enterocyte epithelium up to a vascularized complete epithelium to target different NGRA applications (see Fig. 3). Notably, dynamic culturing of a mucus secreting epithelium with a microbiome might address the need for a host-microbiome interaction model in health and disease. Specifically, intestine-on-chip will further advance studies focussing on oral delivery, toxicokinetic, nutritional metabolism and disease development as it can simulate better the complex in vitro environment rather than static monolayers.

For a dynamically cultured liver models, all approaches improved the study of molecular mechanism impacting efficacy and safety of test chemicals but showed a successful investigation of improved bioactivation, as well as a better emulation of physiological and pathological mechanisms. The long-term maintenance and function was positively impacted by the coculture with vascular cells in all the three, liver, skin and intestine, models. In combination with shear stress, vascular cells introduced a selective biological barrier that mediates tissue homeostasis by supplying the tissues with nutrients and oxygen. Especially for applying liver-onchip in NGRA, vascularisation is suited to enable long-term stability of the tissue culture for repeated exposure, as well as to investigate toxicity mechanisms through biomechanical factors, extracellular (or diffusible) signalling molecules and cell-cell interaction (Wang et al. 2018a, b).

Overall, we conclude that dynamic culturing is not only revolutionising in vitro tissue culturing on-chip but also provides a novel solution for the NGRA toolbox to characterise chemicals and their specific modes of action for toxicity, as well as fill and refine data gaps without generating new animal data (Punt et al. 2020; Hatherell et al. 2020). For the NGRA framework, the reviewed and selected studies demonstrate how OoC provides the opportunity for humancentric toxicokinetic- and dynamic studies to fill and refine data gaps, either as a single emulated organ or as complex fluidically linked multi-organ system. The obtained results can be used to in integrative PBK models and to perform quantitative in vitro to in vivo extrapolations for chemical hazard characterization. However, before the framework shift and regulatory acceptance, the novel technology must still address biological questions that come with device design (e.g., choice of material, layout, perfusion) and tissue engineering (e.g., organ scaling, blood substitutes, chronic and systemic toxicity, culture and assay protocols) to qualify as reliable and validated fit-for-purpose-system. In the long run, OoC bears the potential to not only outperform traditional in vitro methods but also to accelerate the transition to human-based predictive chemical safety assessment.

Acknowledgements All figures were created with BioRender.com. We are thankful for the helpful comments of Kritika Sadh, Maria Baltazar, Carl Westmoreland and Georgia Reynolds from Unilever.

Funding This work was funded via a grant from Unilever (United Kingdom) to Wageningen University and Research (WUR, The Netherlands) for the $\mathrm{PhD}$ project of K.S. Nitsche.

\section{Declarations}

Conflict of interest The authors declare that they have no known competing financial interests or personal relationships that could have appeared to influence the work reported in this paper.

Open Access This article is licensed under a Creative Commons Attribution 4.0 International License, which permits use, sharing, adaptation, distribution and reproduction in any medium or format, as long as you give appropriate credit to the original author(s) and the source, provide a link to the Creative Commons licence, and indicate if changes were made. The images or other third party material in this article are included in the article's Creative Commons licence, unless indicated otherwise in a credit line to the material. If material is not included in the article's Creative Commons licence and your intended use is not permitted by statutory regulation or exceeds the permitted use, you will need to obtain permission directly from the copyright holder. To view a copy of this licence, visit http://creativecommons.org/licenses/by/4.0/.

\section{References}

Abaci HE, Gledhill K, Guo Z et al (2015) Pumpless microfluidic platform for drug testing on human skin equivalents. Lab Chip 15:882-888. https://doi.org/10.1039/c4lc00999a

Abaci HE, Coffman A, Doucet Y et al (2018) Tissue engineering of human hair follicles using a biomimetic developmental approach. Nat Commun 9:5301. https://doi.org/10.1038/ s41467-018-07579-y

Ahn J, Ahn J-H, Yoon S et al (2019) Human three-dimensional in vitro model of hepatic zonation to predict zonal hepatotoxicity. J Biol Eng 13:22. https://doi.org/10.1186/s13036-019-0148-5

Alberti M, Dancik Y, Sriram G et al (2017) Multi-chamber microfluidic platform for high-precision skin permeation testing. Lab Chip 17:1625-1634. https://doi.org/10.1039/c6lc01574c

Ardalani H, Sengupta S, Harms V et al (2019) 3-D culture and endothelial cells improve maturity of human pluripotent stem cell-derived hepatocytes. Acta Biomater 95:371-381. https://doi. org/10.1016/j.actbio.2019.07.047

Artursson P, Borchardt RT (1997) Intestinal drug absorption and metabolism in cell cultures: Caco-2 and beyond. Pharm Res 14:1655-1658

Azizipour N, Avazpour R, Rosenzweig DH et al (2020) Evolution of biochip technology: a review from Lab-on-a-Chip to Organ-ona-Chip. Micromachines 11:599. https://doi.org/10.3390/MI110 60599

Azizgolshani H, Coppeta JR, Vedula EM et al (2021) High-throughput organ-on-chip platform with integrated programmable fluid flow and real-time sensing for complex tissue models in drug 
development workflows. Lab Chip 21:1454-1474. https://doi.org/ 10.1039/D1LC00067E

Balda MS, Matter K (2008) Tight junctions at a glance. J Cell Sci 121:3677-3682. https://doi.org/10.1242/jcs.023887

Baltazar MT, Cable S, Carmichael PL et al (2020) A next-generation risk assessment case study for coumarin in cosmetic products. Toxicol Sci 176:236-252. https://doi.org/10.1093/toxsci/kfaa048

Bauer S, Wennberg Huldt C, Kanebratt KP et al (2017) Functional coupling of human pancreatic islets and liver spheroids on-a-chip: towards a novel human ex vivo type 2 diabetes model. Sci Rep 7:1-11. https://doi.org/10.1038/s41598-017-14815-w

Beaurivage C, Kanapeckaite A, Loomans C et al (2020) Development of a human primary gut-on-a-chip to model inflammatory processes. Sci Rep 10:21475. https://doi.org/10.1038/ s41598-020-78359-2

Beckwitt CH, Clark AM, Wheeler S et al (2018) Liver 'organ on a chip.' Exp Cell Res 363:15-25. https://doi.org/10.1016/j.yexcr. 2017.12.023

Bein A, Shin W, Jalili-Firoozinezhad S et al (2018) Microfluidic organon-a-chip models of human intestine. Cell Mol Gastroenterol Hepatol 5:659-668. https://doi.org/10.1016/J.JCMGH.2017.12. 010

Bell CC, Hendriks DFG, Moro SML et al (2016) Characterization of primary human hepatocyte spheroids as a model system for druginduced liver injury, liver function and disease. Sci Rep 6:25187. https://doi.org/10.1038/srep25187

Bell CC, Dankers ACA, Lauschke VM et al (2018) Comparison of hepatic 2D sandwich cultures and $3 \mathrm{~d}$ spheroids for long-term toxicity applications: a multicenter study. Toxicol Sci 162:655-666. https://doi.org/10.1093/toxsci/kfx289

Bell CC, Chouhan B, Andersson LC et al (2020) Functionality of primary hepatic non-parenchymal cells in a 3D spheroid model and contribution to acetaminophen hepatotoxicity. Arch Toxicol 94:1251-1263. https://doi.org/10.1007/s00204-020-02682-w

Berggren E, White A, Ouedraogo G et al (2017) Ab initio chemical safety assessment: a workflow based on exposure considerations and non-animal methods. Comput Toxicol 4:31-44. https://doi. org/10.1016/j.comtox.2017.10.001

Berthier E, Dostie AM, Lee UN et al (2019) Open microfluidic capillary systems. Anal Chem 91:8739. https://doi.org/10.1021/ACS. ANALCHEM.9B01429

Bhatia SN, Ingber DE (2014) Microfluidic organs-on-chips. Nat Biotechnol 32:760-772. https://doi.org/10.1038/nbt.2989

Bircsak KM, DeBiasio R, Miedel M et al (2021) A 3D microfluidic liver model for high throughput compound toxicity screening in the OrganoPlate®. Toxicology 450:152667. https://doi.org/10. 1016/j.tox.2020.152667

Bock S, Said A, Müller G et al (2018) Characterization of reconstructed human skin containing Langerhans cells to monitor molecular events in skin sensitization. Toxicol in Vitro 46:77-85. https:// doi.org/10.1016/j.tiv.2017.09.019

Bovard D, Sandoz A (2019) How to build your multiorgan-on-a-chip system: a case study. In: Hoeng J, Bovard D, Peitsch MC (ed) Organ-on-a-chip: engineered microenvironments for safety and efficacy testing. Elsevier, pp 463-506. https://doi.org/10.1016/ B978-0-12-817202-5.00015-2

Brinkmann J, Stolpmann K, Trappe S et al (2013) Metabolically competent human skin models: activation and genotoxicity of benzo[a]pyrene. Toxicol Sci 131:351-359. https://doi.org/10. 1093/toxsci/kfs316

Bulutoglu B, Rey-Bedón C, Mert S et al (2020) A comparison of hepato-cellular in vitro platforms to study CYP3A4 induction. PLoS ONE 15:e0229106. https://doi.org/10.1371/JOURNAL. PONE.0229106

Castell JV, Jover R, Martínez-Jiménez CP, Gómez-Lechón MJ (2006) Hepatocyte cell lines: their use, scope and limitations in drug metabolism studies. Expert Opin Drug Metab Toxicol 2:183212. https://doi.org/10.1517/17425255.2.2.183

Chen HJ, Miller P, Shuler ML (2018) A pumpless body-on-a-chip model using a primary culture of human intestinal cells and a 3D culture of liver cells. Lab Chip 18:2036-2046. https://doi. org/10.1039/c81c00111a

Chong SZ, Evrard M, Ng LG (2013) Lights, camera, and action: vertebrate skin sets the stage for immune cell interaction with arthropod-vectored pathogens. Front Immunol. https://doi.org/ 10.3389/fimmu.2013.00286

Costa J, Ahluwalia A (2019) Advances and current challenges in intestinal in vitro model engineering: a digest. Front Bioeng Biotechnol 7:144. https://doi.org/10.3389/fbioe.2019.00144

Cristofalo VJ, Lorenzini A, Allen RG et al (2004) Replicative senescence: a critical review. Mech Ageing Dev 125:827-848. https:// doi.org/10.1016/j.mad.2004.07.010

Cui Y, Claus S, Schnell D, Runge F, MacLean C (2020) In-depth characterization of epiIntestinal microtissue as a model for intestinal drug absorption and metabolism in human. Pharmaceutics 12:405. https://doi.org/10.3390/pharmaceutics12050405

Curto VF, Marchiori B, Hama A et al (2017) Organic transistor platform with integrated microfluidics for in-line multi-parametric in vitro cell monitoring. Microsyst Nanoeng 3:17028. https://doi. org/10.1038/micronano.2017.28

D'Arcangelo E, McGuigan AP (2015) Micropatterning strategies to engineer controlled cell and tissue architecture in vitro. Biotechniques 58:13-23. https://doi.org/10.2144/000114245

Davenport M (2017) Surgery of the liver. bile ducts and pancreas in children. Third Edition. John Wiley \& Sons Inc, Hoboken, NJ, USA, pp 453-471. https://doi.org/10.1201/9781315113791

De Gregorio V, Corrado B, Sbrescia S et al (2020a) Intestine-on-chip device increases ECM remodeling inducing faster epithelial cell differentiation. Biotechnol Bioeng 117:556-566. https://doi.org/ 10.1002/bit.27186

De Gregorio V, Telesco M, Corrado B et al (2020b) Intestine-liver axis on-chip reveals the intestinal protective role on hepatic damage by emulating ethanol first-pass metabolism. Front Bioeng Biotechnol 8:163. https://doi.org/10.3389/fbioe.2020.00163

Deng J, Cong Y, Han X et al (2020) A liver-on-a-chip for hepatoprotective activity assessment. Biomicrofluidics 14:064107. https://doi. org/10.1063/5.0024767

Dent M, Amaral RT, Da Silva PA et al (2018) Principles underpinning the use of new methodologies in the risk assessment of cosmetic ingredients. Comput Toxicol 7:20-26. https://doi.org/10.1016/j. comtox.2018.06.001

Ding C, Chen X, Kang Q, Yan X (2020) Biomedical application of functional materials in organ-on-a-chip. Front Bioeng Biotechnol 8:823. https://doi.org/10.3389/FBIOE.2020.00823

Downs TR, Arlt VM, Barnett BC et al (2021) Effect of 2-acetylaminofluorene and its genotoxic metabolites on DNA adduct formation and DNA damage in 3D reconstructed human skin tissue models. Mutagenesis 36:63-74. https://doi.org/10.1093/mutage/gez044

Duivenvoorde LPM, Louisse J, Pinckaers NET et al (2021) Comparison of gene expression and biotransformation activity of HepaRG cells under static and dynamic culture conditions. Sci Rep 11:10327. https://doi.org/10.1038/s41598-021-89710-6

Dutton JS, Hinman SS, Kim R et al (2019) Primary cell-derived intestinal models: recapitulating physiology. Trends Biotechnol 37:744-760. https://doi.org/10.1016/j.tibtech.2018.12.001

Duval K, Grover H, Han L-H et al (2017) Modeling physiological events in 2D vs. 3D cell culture. Physiology (bethesda) 32:266277. https://doi.org/10.1152/physiol.00036.2016

Ehrlich A, Duche D, Ouedraogo G, Nahmias Y (2019) Challenges and opportunities in the design of liver-on-chip microdevices. Annu Rev Biomed Eng 21:219-239. https://doi.org/10.1146/annur ev-bioeng-060418-052305 
Elzinga J, van der Oost J, de Vos WM, Smidt H (2019) The use of defined microbial communities to model host-microbe interactions in the human gut. Microbiol Mol Biol Rev. https://doi.org/ 10.1128/mmbr.00054-18

Ertel A, Verghese A, Byers SW et al (2006) Pathway-specific differences between tumor cell lines and normal and tumor tissue cells. Mol Cancer 5:55. https://doi.org/10.1186/1476-4598-5-55

Freag MS, Namgung B, Reyna Fernandez ME et al (2021) Human nonalcoholic steatohepatitis on a chip. Hepatol Commun 5:217-233. https://doi.org/10.1002/HEP4.1647

Frombach J, Sonnenburg A, Krapohl BD et al (2018) Lymphocyte surface markers and cytokines are suitable for detection and potency assessment of skin-sensitizing chemicals in an in vitro model of allergic contact dermatitis: the LCSA-ly. Arch Toxicol 92:1495-1505. https://doi.org/10.1007/s00204-018-2164-5

Ganz T (2000) Paneth cells-guardians of the gut cell hatchery. Nat Immunol 1:99-100. https://doi.org/10.1038/77884

Gauglitz GG, Schauber J (2014) Skin: architecture and function. In: Kamolz LP, Lumenta D (eds) Dermal replacements in general, burn, and plastic surgery: tissue engineering in clinical practice., Springer Vienna, Vienna, pp 1-11. https://doi.org/10.1007/ 978-3-7091-1586-2_1

Germain L, Larouche D, Nedelec B et al (2018) Autologous bilayered self-assembled skin substitutes (Sasss) as permanent grafts: a case series of 14 severely burned patients indicating clinical effectiveness. Eur Cells Mater 36:128-141. https://doi.org/10. 22203/eCM.v036a10

Gibbs S, Corsini E, Spiekstra SW et al (2013) An epidermal equivalent assay for identification and ranking potency of contact sensitizers. Toxicol Appl Pharmacol 272:529-541. https://doi.org/10. 1016/j.taap.2013.07.003

Gijzen L, Marescotti D, Raineri E et al (2020) An intestine-on-a-chip model of plug-and-play modularity to study inflammatory processes. SLAS Technol 25:585-597. https://doi.org/10.1177/ 2472630320924999

Gillet J-P, Varma S, Gottesman MM (2013) The clinical relevance of cancer cell lines. J Natl Cancer Inst 105:452-458. https://doi. org/10.1093/jnci/djt007

Gilmour N, Kern PS, Alépée N et al (2020) Development of a next generation risk assessment framework for the evaluation of skin sensitisation of cosmetic ingredients. Regul Toxicol Pharmacol 116:104721. https://doi.org/10.1016/j.yrtph.2020.104721

Gjorevski N, Lutolf MP (2017) Synthesis and characterization of welldefined hydrogel matrices and their application to intestinal stem cell and organoid culture. Nat Protoc 12:2263-2274. https://doi. org/10.1038/nprot.2017.095

Gjorevski N, Avignon B, Gérard R et al (2020) Neutrophilic infiltration in organ-on-a-chip model of tissue inflammation. Lab Chip 20:3365-3374. https://doi.org/10.1039/d0lc00417k

Gledhill K, Guo Z, Umegaki-Arao N et al (2015) Melanin transfer in human 3D Skin equivalents generated exclusively from induced pluripotent stem cells. PLoS ONE 10:e0136713. https://doi.org/ 10.1371/journal.pone.0136713

Goyer B, Pereira U, Magne B et al (2019) Impact of ultraviolet radiation on dermal and epidermal DNA damage in a human pigmented bilayered skin substitute. J Tissue Eng Regen Med 13:2300-2311. https://doi.org/10.1002/term.2959

Grant J, Özkan A, Oh C et al (2021) Simulating drug concentrations in PDMS microfluidic organ chips. Lab Chip 21:3509-3519. https://doi.org/10.1039/D1LC00348H

Grassart A, Malardé V, Gobaa S et al (2019) Bioengineered human organ-on-chip reveals intestinal microenvironment and mechanical forces impacting shigella infection. Cell Host Microbe 26:435-444.e4. https://doi.org/10.1016/j.chom.2019.08.007

Hatherell S, Baltazar MT, Reynolds J et al (2020) Identifying and characterizing stress pathways of concern for consumer safety in next-generation risk assessment. Toxicol Sci 176:11-33. https:// doi.org/10.1093/toxsci/kfaa054

Heringa MB, Park MVDZ, Kienhuis AS, Vandebriel RJ (2020) The value of organs-on-chip for regulatory safety assessment. Altex 37:208-222. https://doi.org/10.14573/altex.1910111

Herland A, Maoz BM, Das D et al (2020) Quantitative prediction of human pharmacokinetic responses to drugs via fluidically coupled vascularized organ chips. Nat Biomed Eng 4:421-436. https://doi.org/10.1038/s41551-019-0498-9

Hilgendorf C, Spahn-Langguth H, Regårdh CG et al (2000) Caco-2 versus Caco-2/HT29-MTX co-cultured cell lines: permeabilities via diffusion, inside- and outside-directed carrier-mediated transport. J Pharm Sci 89:63-75. https://doi.org/10.1002/(SICI) 1520-6017(200001)89:1\%3c63::AID-JPS7\%3e3.0.CO;2-6

Hinman SS, Kim R, Wang Y et al (2020) Microphysiological system design: simplicity is elegance. Curr Opin Biomed Eng 13:94102. https://doi.org/10.1016/j.cobme.2019.12.010

Holmgren G, Sjögren AK, Barragan I et al (2014) Long-term chronic toxicity testing using human pluripotent stem cell-derived hepatocytes. Drug Metab Dispos 42:1401-1406. https://doi.org/10. 1124/dmd.114.059154

HuDMOP®IIONTOX. https://www.iontox.com/hudmop-multipleorgan-system/. Accessed 11 Jan $2022 \mathrm{j}$

HUMIMIC Chip2-TissUse GmbH. https://www.tissuse.com/en/ humimic/chips/humimic-chip2/. Accessed 11 Jan 2022

InSphero Akura ${ }^{\mathrm{TM}}$ flow: transforming drug discovery and development with body-on-a-chip technology|InSphero. https://insphero.com/ blog/insphero-akura-flow-transforming-drug-discovery-devel opment-body-chip-technology/. Accessed 13 Aug 2020

Ishibashi H, Nakamura M, Komori A et al (2009) Liver architecture, cell function, and disease. Semin Immunopathol 31:399-409. https://doi.org/10.1007/s00281-009-0155-6

Ishida S (2020) Requirements for designing organ-on-a-chip platforms to model the pathogenesis of liver disease. In: Hoeng J, Bovard D, Peitsch MC (eds) Organ-on-a-chip. Elsevier, pp 181-213. https://doi.org/10.1016/B978-0-12-817202-5.00005-X

Itoh M, Umegaki-Arao N, Guo Z et al (2013) Generation of 3D skin equivalents fully reconstituted from human induced pluripotent stem cells (iPSCs). PLoS ONE 8:e77673. https://doi.org/10. 1371/journal.pone.0077673

Jalili-Firoozinezhad S, Prantil-Baun R, Jiang A et al (2018) Modeling radiation injury-induced cell death and countermeasure drug responses in a human Gut-on-a-Chip. Cell Death Dis 9:223. https://doi.org/10.1038/s41419-018-0304-8

Jalili-Firoozinezhad S, Gazzaniga FS, Calamari EL et al (2019) A complex human gut microbiome cultured in an anaerobic intestineon-a-chip. Nat Biomed Eng 3:520-531. https://doi.org/10.1038/ s41551-019-0397-0

Jang K-J, Otieno MA, Ronxhi J et al (2019a) Reproducing human and cross-species drug toxicities using a Liver-Chip. Sci Transl Med 11:631002. https://doi.org/10.1126/scitranslmed.aax5516

Jang M, Kleber A, Ruckelshausen T et al (2019b) Differentiation of the human liver progenitor cell line (HepaRG) on a microfluidicbased biochip. J Tissue Eng Regen Med 13:482-494. https://doi. org/10.1002/term.2802

Jellali R, Bricks T, Jacques S et al (2016) Long-term human primary hepatocyte cultures in a microfluidic liver biochip show maintenance of mRNA levels and higher drug metabolism compared with Petri cultures. Biopharm Drug Dispos 37:264-275. https:// doi.org/10.1002/bdd.2010

Jensen C, Teng Y (2020) Is it time to start transitioning from 2D to 3D cell culture? Front Mol Biosci 7:33. https://doi.org/10.3389/ fmolb.2020.00033 
Johansson MEV, Hansson GC (2016) Immunological aspects of intestinal mucus and mucins. Nat Rev Immunol 16:639-649. https:// doi.org/10.1038/nri.2016.88

Jusoh N, Ko J, Jeon NL (2019) Microfluidics-based skin irritation test using in vitro 3D angiogenesis platform. APL Bioeng 3:036101. https://doi.org/10.1063/1.5093975

Kaarj K, Yoon JY (2019) Methods of delivering mechanical stimuli to Organ-on-a-Chip. Micromachines. https://doi.org/10.3390/ mi 10100700

Kandarova H, Hayden PJ (2021) Standardised reconstructed skin models in toxicology and pharmacology: state of the art and future development. In: Schäfer-Korting M, Stuchi Maria-Engler S, Landsiedel R (eds) Organotypic models in drug development. Springer International Publishing, Cham, pp 57-71

Kang YB, Eo J, Mert S et al (2018) Metabolic patterning on a chip: towards in vitro liver zonation of primary rat and human hepatocytes. Sci Rep 8:8951. https://doi.org/10.1038/ s41598-018-27179-6

Kasendra M, Tovaglieri A, Sontheimer-Phelps A et al (2018) Development of a primary human Small Intestine-on-a-Chip using biopsy-derived organoids. Sci Rep 8:2871. https://doi.org/10. 1038/s41598-018-21201-7

Kasendra M, Luc R, Yin J et al (2020) Duodenum intestine-chip for preclinical drug assessment in a human relevant model. Elife 9:1-23. https://doi.org/10.7554/eLife.50135

Kasuya J, Sudo R, Mitaka T et al (2011) Hepatic stellate cell-mediated three-dimensional hepatocyte and endothelial cell triculture model. Tissue Eng Part A 17:361-370. https://doi.org/10.1089/ ten.tea.2010.0033

Kim HJ, Li H, Collins JJ, Ingber DE (2016) Contributions of microbiome and mechanical deformation to intestinal bacterial overgrowth and inflammation in a human gut-on-a-chip. Proc Natl Acad Sci USA 113:E7-E15. https://doi.org/10.1073/pnas.15221 93112

Kim J, Koo B-K, Knoblich JA (2020) Human organoids: model systems for human biology and medicine. Nat Rev Mol Cell Biol 21:571-584. https://doi.org/10.1038/s41580-020-0259-3

Kohl C (2008) The importance of gut wall metabolism in determining drug bioavailability. In: Mannhold R, Kubinyi H, Folkers G (eds) Drug bioavailability: estimation of solubility, permeability, absorption and bioavailability. Wiley Blackwell, pp 333-357. https://doi.org/10.1002/9783527623860.ch12

Kondo S, Mizuno S, Hashita T et al (2020) Establishment of a novel culture method for maintaining intestinal stem cells derived from human induced pluripotent stem cells. Biol Open. https://doi.org/ 10.1242/BIO.049064

Kosten IJ, Spiekstra SW, de Gruijl TD, Gibbs S (2015) MUTZ-3 derived Langerhans cells in human skin equivalents show differential migration and phenotypic plasticity after allergen or irritant exposure. Toxicol Appl Pharmacol 287:35-42. https:// doi.org/10.1016/j.taap.2015.05.017

Kostrzewski T, Cornforth T, Snow SA et al (2017) Three-dimensional perfused human in vitro model of non-alcoholic fatty liver disease. World J Gastroenterol 23:204-215. https://doi.org/10.3748/ wjg.v23.i2.204

Kostrzewski T, Maraver P, Ouro-Gnao L et al (2020) A microphysiological system for studying nonalcoholic steatohepatitis. Hepatol Commun 4:77-91. https://doi.org/10.1002/hep4.1450

Kramer NI, Di Consiglio E, Blaauboer BJ, Testai E (2015) Biokinetics in repeated-dosing in vitro drug toxicity studies. Toxicol in Vitro 30:217-224. https://doi.org/10.1016/j.tiv.2015.09.005

Kühnl J, Tao TP, Brandmair K et al (2021) Characterization of application scenario-dependent pharmacokinetics and pharmacodynamic properties of permethrin and hyperforin in a dynamic skin and liver multi-organ-chip model. Toxicology 448:152637. https://doi.org/10.1016/j.tox.2020.152637
Kulthong K, Duivenvoorde L, Mizera BZ et al (2018) Implementation of a dynamic intestinal gut-on-a-chip barrier model for transport studies of lipophilic dioxin congeners. RSC Adv 8:32440-32453. https://doi.org/10.1039/C8RA05430D

Kulthong K, Duivenvoorde L, Sun H et al (2020) Microfluidic chip for culturing intestinal epithelial cell layers: characterization and comparison of drug transport between dynamic and static models. Toxicol in Vitro 65:104815. https://doi.org/10.1016/j. tiv.2020.104815

Kurth F, Györvary E, Heub S et al (2020) Organs-on-a-chip engineering. In: Hoeng J, Bovard D, Peitsch MC (eds) organ-on-a-chip. Elsevier, pp 47-130. https://doi.org/10.1016/B978-0-12-8172025.00003-6

Kwak BS, Jin SP, Kim SJ et al (2020) Microfluidic skin chip with vasculature for recapitulating the immune response of the skin tissue. Biotechnol Bioeng 117:1853-1863. https://doi.org/10. 1002/bit. 27320

Lasli S, Kim H, Lee K et al (2019) A human liver-on-a-chip platform for modeling nonalcoholic fatty liver disease. Adv Biosyst 3:e1900104. https://doi.org/10.1002/adbi.201900104

Lee SH, Jun BH (2019) Advances in dynamic microphysiological organ-on-a-chip: design principle and its biomedical application. J Ind Eng Chem 71:65-77

Lee CS, Nam G, Bae IH, Park J (2019a) Whitening efficacy of ginsenoside F1 through inhibition of melanin transfer in cocultured human melanocytes-keratinocytes and three-dimensional human skin equivalent. J Ginseng Res 43:300-304. https://doi.org/10. 1016/j.jgr.2017.12.005

Lee SH, Choi N, Sung JH (2019b) Pharmacokinetic and pharmacodynamic insights from microfluidic intestine-on-a-chip models. Expert Opin Drug Metab Toxicol 15:1005-1019. https://doi.org/ 10.1080/17425255.2019.1700950

Leite SB, Roosens T, El Taghdouini A et al (2016) Novel human hepatic organoid model enables testing of drug-induced liver fibrosis in vitro. Biomaterials 78:1-10. https://doi.org/10.1016/j. biomaterials.2015.11.026

Lembong J, Lerman MJ, Kingsbury TJ et al (2018) A fluidic culture platform for spatially patterned cell growth, differentiation, and cocultures. Tissue Eng Part A 24:1715-1732. https://doi.org/10. 1089/ten.tea.2018.0020

Li X, George SM, Vernetti L et al (2018) A glass-based, continuously zonated and vascularized human liver acinus microphysiological system (vLAMPS) designed for experimental modeling of diseases and ADME/TOX. Lab Chip 18:2614-2631. https://doi. org/10.1039/c81c00418h

Li F, Cao L, Parikh S, Zuo R (2020) Three-dimensional spheroids with primary human liver cells and differential roles of Kupffer cells in drug-induced liver injury. J Pharm Sci 109:1912-1923. https:// doi.org/10.1016/j.xphs.2020.02.021

Liévin-Le Moal V, Servin AL (2006) The front line of enteric host defense against unwelcome intrusion of harmful microorganisms: mucins, antimicrobial peptides, and microbiota. Clin Microbiol Rev 19:315-337. https://doi.org/10.1128/CMR.19.2.315-337. 2006

Lin DSY, Rajasekar S, Marway MK, Zhang B (2021) From model system to therapy: scalable production of perfusable vascularized liver spheroids in "Open-Top" 384-well plate. ACS Biomater Sci Eng 7:2964-2972. https://doi.org/10.1021/acsbiomaterials. $0 \mathrm{c} 00236$

Long TJ, Cosgrove PA, Dunn RT et al (2016) Modeling therapeutic antibody-small molecule drug-drug interactions using a threedimensional perfusable human liver coculture platform. Drug Metab Dispos 44:1940-1948. https://doi.org/10.1124/dmd.116. 071456 
Low LA, Mummery C, Berridge BR et al (2021) Organs-on-chips: into the next decade. Nat Rev Drug Discov 20:345-361. https://doi. org/10.1038/s41573-020-0079-3

Lu FC, Kacew S (2002) Lu's basic toxicology: fundamentals, target organs and risk assessment, 4th edn. CRC Press, Taylor \& Francis. London. https://doi.org/10.1201/9781003026976

Ma LD, Wang YT, Wang JR et al (2018) Design and fabrication of a liver-on-a-chip platform for convenient, highly efficient, and safe: In situ perfusion culture of 3D hepatic spheroids. Lab Chip 18:2547-2562. https://doi.org/10.1039/c81c00333e

Maass C, Stokes CL, Griffith LG, Cirit M (2017) Multi-functional scaling methodology for translational pharmacokinetic and pharmacodynamic applications using integrated microphysiological systems (MPS). Integr Biol (UK) 9:290-302. https://doi.org/10. 1039/c6ib00243a

Madden LR, Nguyen TV, Garcia-Mojica S et al (2018) Bioprinted 3D primary human intestinal tissues model aspects of native physiology and ADME/tox functions. iScience 2:156-167. https://doi. org/10.1016/j.isci.2018.03.015

Mäki A-J, Hemmilä S, Hirvonen J et al (2015) Modeling and experimental characterization of pressure drop in gravity-driven microfluidic systems. J Fluids Eng. https://doi.org/10.1115/1.4028501

Marin TM, de Carvalho IN, Rocco SA et al (2019) Acetaminophen absorption and metabolism in an intestine/liver microphysiological system. Chem Biol Interact 299:59-76. https://doi.org/10. 1016/j.cbi.2018.11.010

Martínez-Maqueda D, Miralles B, Recio I (2015) HT29 cell line. Springer International Publishing, Cham

Marx U (2020) Biology-inspired microphysiological systems to advance medicines for patient benefit and animal welfare. Altex 37:365-394. https://doi.org/10.14573/altex.2001241

Maschmeyer I, Hasenberg T, Jaenicke A et al (2015) Chip-based human liver-intestine and liver-skin co-cultures-a first step toward systemic repeated dose substance testing in vitro. Eur J Pharm Biopharm 95:77-87. https://doi.org/10.1016/j.ejpb.2015.03.002

Mastrangeli M, Millet S, Mummery C et al (2019) Building blocks for a European organ-on-chip roadmap. Altex 36:481-492. https:// doi.org/10.14573/ALTEX.1905221

Materne E-M, Maschmeyer I, Lorenz AK et al (2015) The multi-organ chip-a microfluidic platform for long-term multi-tissue coculture. J Visual Exp Jove 2015:e52526. https://doi.org/10.3791/ 52526

Mathes SH, Ruffner H, Graf-Hausner U (2014) The use of skin models in drug development. Adv Drug Deliv Rev 69-70:81-102. https://doi.org/10.1016/j.addr.2013.12.006

McGill MR, Williams CD, Jaeschke H (2015) Liver toxicology. In: Abou-Donia MB (ed) Mammalian toxicology. Wiley, Hoboken, pp 453-471. https://doi.org/10.1002/9781118683484

McGinnity DF, Grime K (2017) ADME optimization in drug discovery. In: Comprehensive medicinal chemistry III. Elsevier, pp 34-44. https://doi.org/10.1016/B978-0-12-409547-2.12365-0

Mehling A, Adriaens E, Casati S et al (2019) In vitro RHE skin sensitisation assays: applicability to challenging substances. Regul Toxicol Pharmacol 108:104473. https://doi.org/10.1016/J. YRTPH.2019.104473

Meier F, Freyer N, Brzeszczynska J et al (2017) Hepatic differentiation of human iPSCs in different 3D models: a comparative study. Int J Mol Med 40:1759-1771. https://doi.org/10.3892/ijmm.2017. 3190

Mestecky J, Strober W, Russell MW et al (2015) Mucosal immunology, 4th edn. Elsevier, pp 489-51. https://doi.org/10.1016/B978-0-12415847-4.00025-2

Moniz T, Costa Lima SA, Reis S (2020) Human skin models: from healthy to disease-mimetic systems; characteristics and applications. Br J Pharmacol 177:4314-4329. https://doi.org/10.1111/ BPH.15184
Mori N, Morimoto Y, Takeuchi S (2017) Skin integrated with perfusable vascular channels on a chip. Biomaterials 116:48-56. https://doi.org/10.1016/j.biomaterials.2016.11.031

Mummery C, van Meer B, van den Eijnden-van Raaij J, van de Graaf A (2020) Towards new research models for studying disease and finding treatments. Mini organs-on-chips. Cahier 3. vol 39, Dutch Foundation BWM. pp 21-37

Naito C, Yamaguchi T, Katsumi H et al (2019) Utility of three-dimensional skin from human-induced pluripotent stem cells as a tool to evaluate transdermal drug permeation. J Pharm Sci 108:35243527. https://doi.org/10.1016/j.xphs.2019.07.006

Naumovska E, Aalderink G, Wong Valencia C et al (2020) Direct onchip differentiation of intestinal tubules from induced pluripotent stem cells. Int J Mol Sci 21:4964. https://doi.org/10.3390/ijms2 1144964

Ng WL, Yeong WY (2019) The future of skin toxicology testingthree-dimensional bioprinting meets microfluidics. Int J Bioprint 5:237. https://doi.org/10.18063/ijb.v5i2.1.237

Nguyen DG, Funk J, Robbins JB et al (2016) Bioprinted 3D primary liver tissues allow assessment of organ-level response to clinical drug induced toxicity in vitro. PLoS ONE 11:e0158674. https:// doi.org/10.1371/journal.pone.0158674

OECD (2021a) Test guideline no. 498 in vitro phototoxicity: reconstructed human epidermis phototoxicity test method. OECD Guidelines Testing Chem Sect 4:1-27. https://doi.org/10.1787/ $7 \mathrm{~b} 2 \mathrm{f} 9 \mathrm{ea0}-\mathrm{en}$

OECD (2021b) Guideline no. 497 guideline on defined approaches for skin sensitisation section 4 health effects. OECD guidelines for the testing of chemicals, section 4. OECD Publishing, Paris. https://doi.org/10.1787/b92879a4-en

OECD (2021c) Test No. 439: in vitro skin irritation: reconstructed human epidermis test method. OECD guidelines for the testing of chemicals, section 4. OECD Publishing, Paris. https://doi.org/ 10.1787/9789264242845-en

Organ-on-a-chip|Micronit. https://www.micronit.com/products/organon-a-chip. Accessed 14 Aug 2020f

Organs-on-Chips Technology-Emulate. https://www.emulatebio.com/ our-technology. Accessed 13 Aug 2020

OrganoPlate ${ }^{\circledR}$ 3-lanelMimetas. https://mimetas.com/page/organoplat e®-3-lane. Accessed 11 Aug 2020

Ozawa T, Takayama K, Okamoto R et al (2015) Generation of enterocyte-like cells from human induced pluripotent stem cells for drug absorption and metabolism studies in human small intestine. Sci Rep 5:1-11. https://doi.org/10.1038/srep16479

Petrova A, Capalbo A, Jacquet L et al (2016) Induced pluripotent stem cell differentiation and three-dimensional tissue formation attenuate clonal epigenetic differences in trichohyalin. Stem Cells Dev 25:1366-1375. https://doi.org/10.1089/scd.2016.0156

PhysioMimix ${ }^{\mathrm{TM}} \mid \mathrm{CN}$ BIO Innovations. https://cn-bio.com/physiomimi xooc/. Accessed 14 Aug 2020

Picollet-D'hahan N, Zuchowska A, Lemeunier I, Le Gac S (2021) Multiorgan-on-a-chip: a systemic approach to model and decipher inter-organ communication. Trends Biotechnol 39:788-810. https://doi.org/10.1016/j.tibtech.2020.11.014

Piergiovanni M, Leite SB, Corvi R, Whelan M (2021) Standardisation needs for organ on chip devices. Lab Chip 21:2857-2868. https:// doi.org/10.1039/d1lc00241d

Pires De Mello CP, Carmona-Moran C, Mcaleer CW, et al (2020) Lab on a chip microphysiological heart-liver body-on-a-chip system with a skin mimic for evaluating topical drug delivery $† .20: 749$. https://doi.org/10.1039/c91c00861f

Poisson J, Lemoinne S, Boulanger C et al (2017) Liver sinusoidal endothelial cells: physiology and role in liver diseases. J Hepatol 66:212-227 
Products-Bi/ond. https://www.gobiond.com/products/. Accessed 14 Aug 2020

Proença S, Escher BI, Fischer FC et al (2021) Effective exposure of chemicals in in vitro cell systems: a review of chemical distribution models. Toxicol in Vitro 73:105133. https://doi.org/10. 1016/J.TIV.2021.105133

Punt A, Bouwmeester H, Blaauboer BJ et al (2020) New approach methodologies (NAMs) for human-relevant biokinetics predictions. Meeting the paradigm shift in toxicology towards an animal-free chemical risk assessment. Altex 37:607-622. https:// doi.org/10.14573/altex.2003242

Ramadan Q, Ting FCW (2016) In vitro micro-physiological immunecompetent model of the human skin. Lab Chip 16:1899-1908. https://doi.org/10.1039/c6lc00229c

Ramaiahgari SC, Ferguson SS (2019) Organotypic 3D HepaRG liver model for assessment of drug-induced cholestasis. Methods Mol Biol 1981:313-323. https://doi.org/10.1007/978-1-4939-94205_20

Ramme AP, Koenig L, Hasenberg T et al (2019) Autologous induced pluripotent stem cell-derived four-organ-chip. Future Sci OA 5:413-2056. https://doi.org/10.2144/fsoa-2019-0065

Rao JN, Wang J-Y (2010) Regulation of gastrointestinal mucosal growth. San Rafael (CA): Morgan \& Claypool Life Sciences; 2010. Intestinal Architecture and Development. https://www. ncbi.nlm.nih.gov/books/NBK54098/

Reijnders CMA, Van Lier A, Roffel S et al (2015) Development of a full-thickness human skin equivalent in vitro model derived from TERT-immortalized keratinocytes and fibroblasts. Tissue Eng Part A 21:2448-2459. https://doi.org/10.1089/ten.tea.2015.0139

Reisinger K, Blatz V, Brinkmann J et al (2018) Validation of the 3D skin comet assay using full thickness skin models: transferability and reproducibility. Mutat Res 827:27-41. https://doi.org/10. 1016/j.mrgentox.2018.01.003

Renggli K, Frey O (2020) Design and engineering of multiorgan systems. Elsevier. pp 393-427. https://doi.org/10.1016/B978-0-12817202-5.00012-7

Rennert K, Steinborn S, Gröger M et al (2015) A microfluidically perfused three dimensional human liver model. Biomaterials 71:119-131. https://doi.org/10.1016/j.biomaterials.2015.08.043

Risueño I, Valencia L, Jorcano JL, Velasco D (2021) Skin-on-a-chip models: general overview and future perspectives. APL Bioeng 5:1-12. https://doi.org/10.1063/5.0046376

Ronaldson-Bouchard K, Vunjak-Novakovic G (2018) Organs-on-achip: a fast track for engineered human tissues in drug development. Cell Stem Cell 22:310-324

Rothbauer M, Zirath H, Ertl P (2018) Recent advances in microfluidic technologies for cell-to-cell interaction studies. Lab Chip 18:249-270. https://doi.org/10.1039/C7LC00815E

Rusyn I, Roth A (2021) Editorial overview of the special issue on application of tissue chips in toxicology. Toxicology 450:152687. https://doi.org/10.1016/J.TOX.2021.152687

Sakolish C, Reese CE, Luo YS et al (2021) Analysis of reproducibility and robustness of a human microfluidic four-cell liver acinus microphysiology system (LAMPS). Toxicology 448:152651. https://doi.org/10.1016/j.tox.2020.152651

Santbergen MJC, van der Zande M, Gerssen A et al (2020) Dynamic in vitro intestinal barrier model coupled to chip-based liquid chromatography mass spectrometry for oral bioavailability studies. Anal Bioanal Chem 412:1111-1122. https://doi.org/10.1007/ s00216-019-02336-6

Schäfer-Korting M, Bock U, Gamer A et al (2006) Reconstructed human epidermis for skin absorption testing: Results of the German prevalidation study. ATLA Altern Lab Anim 34:283-294. https://doi.org/10.1177/026119290603400312

Schellenberger MT, Bock U, Hennen J et al (2019) A coculture system composed of THP-1 cells and 3D reconstructed human epidermis to assess activation of dendritic cells by sensitizing chemicals after topical exposure. Toxicol in Vitro 57:62-66. https://doi. org/10.1016/j.tiv.2019.02.002

Schepers A, Li C, Chhabra A et al (2016) Engineering a perfusable 3D human liver platform from iPS cells. Lab Chip 16:2644-2653. https://doi.org/10.1039/c6lc00598e

Schimek K, Hsu H-H, Boehme M et al (2018) Bioengineering of a fullthickness skin equivalent in a 96-well insert format for substance permeation studies and organ-on-a-chip applications. Bioengineering 5:43. https://doi.org/10.3390/bioengineering5020043

Schmidt FF, Nowakowski S, Kluger PJ (2020) Improvement of a threelayered in vitro skin model for topical application of irritating substances. Front Bioeng Biotechnol 8:388. https://doi.org/10. 3389/fbioe.2020.00388

Seiler KM, Bajinting A, Alvarado DM et al (2020) Patient-derived small intestinal myofibroblasts direct perfused physiologically responsive capillary development in a microfluidic Guton-a-Chip Model. Sci Rep 10:1-14. https://doi.org/10.1038/ s41598-020-60672-5

Sharma R, Young C, Neu J (2010) Molecular modulation of intestinal epithelial barrier: contribution of microbiota. J Biomed Biotechnol 2010:305879. https://doi.org/10.1155/2010/305879

Shin W, Hackley LA, Kim HJ (2020) "Good Fences Make Good Neighbors": how does the human gut microchip unravel mechanism of intestinal inflammation? Gut Microbes 11:581-586. https://doi. org/10.1080/19490976.2019.1626684

SkinEthic RHE Reconstructed Human Epidermis. https://www.episk in.com/RHE-LC. Accessed 25 Aug 2020

Soenksen LR, Kassis T, Noh M et al (2018) Closed-loop feedback control for microfluidic systems through automated capacitive fluid height sensing. Lab Chip 18:902-914. https://doi.org/10. 1039/c7lc01223c

Song HJ, Lim HY, Chun W et al (2018) Development of 3D skinequivalent in a pump-less microfluidic chip. J Ind Eng Chem 60:355-359. https://doi.org/10.1016/j.jiec.2017.11.022

Sontheimer-Phelps A, Chou DB, Tovaglieri A et al (2020) Human colon-on-a-chip enables continuous in vitro analysis of colon mucus layer accumulation and physiology. Cmgh 9:507-526. https://doi.org/10.1016/j.jcmgh.2019.11.008

Soto-Gutierrez A, Gough A, Vernetti LA et al (2017) Pre-clinical and clinical investigations of metabolic zonation in liver diseases: the potential of microphysiology systems. Exp Biol Med (maywood) 242:1605-1616. https://doi.org/10.1177/1535370217707731

Sriram G, Alberti M, Dancik Y et al (2018) Full-thickness human skin-on-chip with enhanced epidermal morphogenesis and barrier function. Mater Today 21:326-340. https://doi.org/10.1016/j. mattod.2017.11.002

Sunuwar L, Yin J, Kasendra M et al (2019) Mechanical stimuli affect Escherichia coli heat-stable enterotoxin-cyclic gmp signaling in a human enteroid intestine-chip model downloaded from. https:// doi.org/10.1128/IAI.00866-19

Swift B, Pfeifer ND, Brouwer KLR (2010) Sandwich-cultured hepatocytes: an in vitro model to evaluate hepatobiliary transporterbased drug interactions and hepatotoxicity. Drug Metab Rev 42:446. https://doi.org/10.3109/03602530903491881

Tao TP, Brandmair K, Gerlach S et al (2021) Demonstration of the firstpass metabolism in the skin of the hair dye, 4-amino-2-hydroxytoluene, using the Chip2 skin-liver microphysiological model. J Appl Toxicol. https://doi.org/10.1002/jat.4146

Teimouri A, Yeung P, Agu R (2019) 2D vs. 3D cell culture models for in vitro topical (dermatological) medication testing. In: Mehanna RA (ed) Cell culture. IntechOpen. https://doi.org/10.5772/intec hopen.79868

The ParVivo ${ }^{\mathrm{TM}}$ Organ-on-Chip TechnologylNortis Bio. https://www. nortisbio.com/pages/technology. Accessed 14 Aug 2020i 
The QV900IIdeal for high-content experiments and industrial uselKirkstall Ltd. https://www.kirkstall.com/QV900/. Accessed 14 Aug 2020

Thélu A, Catoire S, Kerdine-Römer S (2020) Immune-competent in vitro co-culture models as an approach for skin sensitisation assessment. Toxicol In Vitro 62: https://doi.org/10.1016/j.tiv. 2019.104691

Theobald J, Ghanem A, Wallisch P et al (2018) Liver-kidney-on-chip to study toxicity of drug metabolites. ACS Biomater Sci Eng 4:78-89. https://doi.org/10.1021/acsbiomaterials.7b00417

Thomas RS, Bahadori T, Buckley TJ et al (2019) The next generation blueprint of computational toxicology at the US Environmental Protection Agency. Toxicol Sci 169:317. https://doi.org/10.1093/ TOXSCI/KFZ058

Torras N, García-Díaz M, Fernández-Majada V, Martínez E (2018) Mimicking epithelial tissues in three-dimensional cell culture models. Front Bioeng Biotechnol 6:197

Tsamandouras N, Chen WLK, Edington CD et al (2017) Integrated gut and liver microphysiological systems for quantitative in vitro pharmacokinetic studies. AAPS J 19:1499-1512. https://doi.org/ 10.1208/s12248-017-0122-4

Turner MR, Balu-Iyer SV (2018) Challenges and opportunities for the subcutaneous delivery of therapeutic proteins. J Pharm Sci 107:1247-1260. https://doi.org/10.1016/j.xphs.2018.01.007

Underhill GH, Khetani SR (2018) Advances in engineered human liver platforms for drug metabolism studies. Drug Metab Dispos 46:1626-1637. https://doi.org/10.1124/dmd.118.083295

van den Broek LJ, Bergers LIJC, Reijnders CMA, Gibbs S (2017) Progress and future prospectives in skin-on-chip development with emphasis on the use of different cell types and technical challenges. Stem Cell Rev Rep 13:418-429. https://doi.org/10. 1007/s12015-017-9737-1

Verma A, Verma M, Singh A (2020) Animal tissue culture principles and applications. In: Singh A (ed) Animal biotechnology. Elsevier, pp 269-293. https://doi.org/10.1016/B978-0-12-811710-1.00012-4

Vernetti LA, Senutovitch N, Boltz R et al (2016) A human liver microphysiology platform for investigating physiology, drug safety, and disease models. Exp Biol Med 241:101-114. https://doi.org/ $10.1177 / 1535370215592121$

Vernetti L, Gough A, Baetz N et al (2017) Functional coupling of human microphysiology systems: intestine, liver, kidney proximal tubule, blood-brain barrier and skeletal muscle. Sci Rep 7:1-15. https://doi.org/10.1038/srep42296

Wang X, Sun Q, Pei J (2018a) Microfluidic-based 3D engineered microvascular networks and their applications in vascularized microtumor models. Micromachines 9:493. https://doi.org/10. 3390/MI9100493
Wang Y, Wang H, Deng P et al (2018b) In situ differentiation and generation of functional liver organoids from human iPSCs in a 3D perfusable chip system. Lab Chip 18:3606-3616. https://doi. org/10.1039/C8LC00869H

Wnorowski A, Yang H, Wu JC (2019) Progress, obstacles, and limitations in the use of stem cells in organ-on-a-chip models. Adv Drug Deliv Rev 140:3-11

Workman MJ, Gleeson JP, Troisi EJ et al (2018) Enhanced utilization of induced pluripotent stem cell-derived human intestinal organoids using microengineered chips. CMGH 5:669-677.e2. https://doi.org/10.1016/j.jcmgh.2017.12.008

Wu Q, Liu J, Wang X et al (2020) Organ-on-a-chip: recent breakthroughs and future prospects. BioMed Eng Online 19:9. https:// doi.org/10.1186/s12938-020-0752-0

Wufuer M, Lee GH, Hur W et al (2016) Skin-on-a-chip model simulating inflammation, edema and drug-based treatment. Sci Rep 6:1-12. https://doi.org/10.1038/srep37471

Xiang Y, Wen H, Yu Y et al (2020) Gut-on-chip: recreating human intestine in vitro. J Tissue Eng 11:204173142096531. https:// doi.org/10.1177/2041731420965318

Zhang Y, Zheng L, Tuo J et al (2017a) Analysis of PM2.5-induced cytotoxicity in human $\mathrm{HaCaT}$ cells based on a microfluidic system. Toxicol in Vitro 43:1-8. https://doi.org/10.1016/j.tiv.2017.04.018

Zhang YS, Aleman J, Shin SR et al (2017b) Multisensor-integrated organs-on-chips platform for automated and continual in situ monitoring of organoid behaviors. Proc Natl Acad Sci USA 114:E2293-E2302. https://doi.org/10.1073/pnas.1612906114

Zhang B, Korolj A, Lai BFL, Radisic M (2018) Advances in organ-ona-chip engineering. Nat Rev Mater 3:257-278. https://doi.org/10. 1038/s41578-018-0034-7

Zhang H, Whalley RD, Ferreira AM, Dalgarno K (2020) High throughput physiological micro-models for in vitro pre-clinical drug testing: a review of engineering systems approaches. Progress Biomed Eng 2:022001. https://doi.org/10.1088/2516-1091/ab7cc4

Zhao Y, Kankala RK, Bin WS, Chen AZ (2019) Multi-organs-on-chips: towards long-term biomedical investigations. Molecules 24:675

Zuchowska A, Kwapiszewska K, Chudy M et al (2017) Studies of anticancer drug cytotoxicity based on long-term HepG2 spheroid culture in a microfluidic system. Electrophoresis 38:1206-1216. https://doi.org/10.1002/elps.201600417

Publisher's Note Springer Nature remains neutral with regard to jurisdictional claims in published maps and institutional affiliations. 